\title{
EXECUÇÃO DO PROGRAMA DE AQUISIÇÃO DE ALIMENTOS NOS MUNICÍPIOS BRASILEIROS
}

Regina Helena Rosa Sambuichi Ana Flávia Cordeiro de Almeida Gabriela Perin Iracema Ferreira de Moura Paulo Sergio Cândido Alves

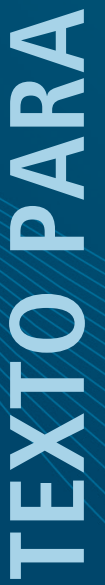





\section{TEXTO PARA DISCUSSÃO}

Brasília, outubro de 2020

\section{EXECUÇÃO DO PROGRAMA DE AQUISIÇÃO DE ALIMENTOS} NOS MUNICÍPIOS BRASILEIROS

Regina Helena Rosa Sambuichi'

Ana Flávia Cordeiro de Almeida²

Gabriela Perin ${ }^{3}$

Iracema Ferreira de Moura ${ }^{4}$

Paulo Sergio Cândido Alves ${ }^{5}$

1. Técnica de planejamento e pesquisa na Diretoria de Estudos e Políticas Regionais, Urbanas e Ambientais (Dirur) do Ipea. E-mail: regina.sambuichi@ipea.gov.br.

2. Pesquisadora do Subprograma de Pesquisa para o Desenvolvimento Nacional (PNPD) na Dirur/lpea.E-mail: ana.cordeiro@ ipea.gov.br.

3. Pesquisadora do PNPD na Dirur/lpea. E-mail: gabriela.perin@ipea.gov.br.

4. Analista técnica de políticas sociais do Ministério da Saúde (MS).E-mail: iracema.moura@saude.gov.br.

5. Coordenador-geral de Articulação Federativa para o Abastecimento Alimentar no Ministério da Cidadania. E-mail: paulo.alves@cidadania.gov.br. 


\section{Governo Federal}

Ministério da Economia

Ministro Paulo Guedes

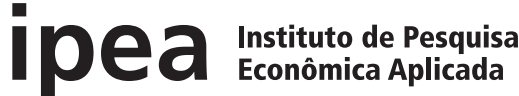

Fundação pública vinculada ao Ministério da Economia, o Ipea fornece suporte técnico e institucional às ações governamentais - possibilitando a formulação de inúmeras políticas públicas e programas de desenvolvimento brasileiros - e disponibiliza, para a sociedade, pesquisas e estudos realizados por seus técnicos.

\section{Presidente}

Carlos von Doellinger

Diretor de Desenvolvimento Institucional Manoel Rodrigues Junior

Diretora de Estudos e Políticas do Estado, das Instituições e da Democracia

Flávia de Holanda Schmidt

\section{Diretor de Estudos e Políticas}

Macroeconômicas

José Ronaldo de Castro Souza Júnior

Diretor de Estudos e Políticas Regionais, Urbanas e Ambientais

Nilo Luiz Saccaro Júnior

Diretor de Estudos e Políticas Setoriais de Inovação e Infraestrutura

André Tortato Rauen

Diretora de Estudos e Políticas Sociais

Lenita Maria Turchi

Diretor de Estudos e Relações Econômicas

e Políticas Internacionais

Ivan Tiago Machado Oliveira

\footnotetext{
Assessor-chefe de Imprensa

e Comunicação (substituto)

João Cláudio Garcia Rodrigues Lima

Ouvidoria: http://www.ipea.gov.br/ouvidoria

URL: http://www.ipea.gov.br
}

\section{Texto para Discussão}

Publicação seriada que divulga resultados de estudos e pesquisas em desenvolvimento pelo Ipea com o objetivo de fomentar o debate e oferecer subsídios à formulação e avaliação de políticas públicas.

(C) Instituto de Pesquisa Econômica Aplicada - ipea 2020

Texto para discussão / Instituto de Pesquisa Econômica Aplicada.- Brasília : Rio de Janeiro : Ipea, 1990-

ISSN 1415-4765

1.Brasil. 2.Aspectos Econômicos. 3.Aspectos Sociais. I. Instituto de Pesquisa Econômica Aplicada.

CDD 330.908

As publicações do Ipea estão disponíveis para download gratuito nos formatos PDF (todas) e EPUB (livros e periódicos). Acesse: http://www.ipea.gov.br/portal/publicacoes

As opiniões emitidas nesta publicação são de exclusiva e inteira responsabilidade dos autores, não exprimindo, necessariamente, o ponto de vista do Instituto de Pesquisa Econômica Aplicada ou do Ministério da Economia.

É permitida a reprodução deste texto e dos dados nele contidos, desde que citada a fonte. Reproduções para fins comerciais são proibidas.

JEL: Q18. 


\section{SUMÁRIO}

SINOPSE

ABSTRACT

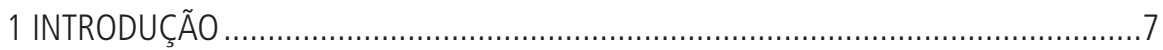

20 PROGRAMA DE AQUISIÇÃO DE ALIMENTOS (PAA) ........................................

З MÉTODOS

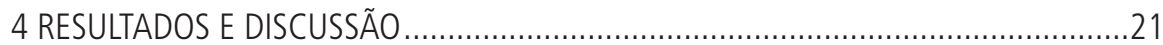

5 O PANORAMA E AS PERSPECTIVAS DO PAA NA ATUALIDADE............................40

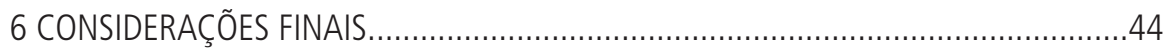

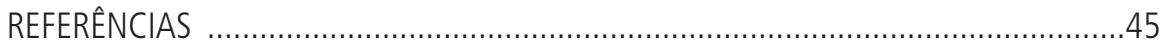

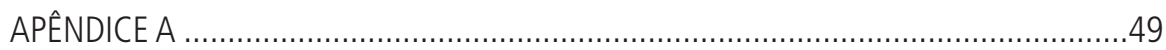





\section{SINOPSE}

Com o objetivo de incentivar a agricultura familiar e promover a segurança alimentar e nutricional, o Programa de Aquisição de Alimentos (PAA) adquire produtos diretamente dos agricultores familiares e de suas organizaçôes, para atender à população em situação de vulnerabilidade por meio da doação desses alimentos. Este estudo realizou uma análise quantitativa da execução do PAA no período de 2011 a 2018, buscando, principalmente, identificar fatores relacionados ao acesso dos municípios ao programa, além de analisar a sua focalização e suas potencialidades para auxiliar no enfrentamento aos desafios que se apresentam na atualidade. Os resultados mostraram que o programa beneficiou mais de 450 mil de agricultores familiares no período, adquirindo 2 milhóes de toneladas de alimentos e conseguindo atingir beneficiários em cerca de $83 \%$ dos municípios brasileiros. A probabilidade de acesso foi maior para municípios com menor desenvolvimento econômico, menos urbanos, com mais agricultores familiares e pertencentes às regiốes Norte e Nordeste, o que indica que o programa está tendo eficácia na sua focalizaçáo - atender prioritariamente às regiôes mais carentes de desenvolvimento rural. Esses dados corroboram os estudos encontrados na literatura que apontam o PAA como um importante canal de comercialização para a agricultura familiar, capaz de promover o aumento da renda, a inclusão produtiva e a dinamização da economia local, além de contribuir para a segurança alimentar e nutricional. Dessa forma, acredita-se que o programa seja uma ferramenta relevante a ser utilizada como instrumento mitigador de efeitos negativos, nos âmbitos econômico e social, gerados pelas crises atuais. Observou-se, porém, uma expressiva diminuição dos recursos aplicados no PAA nos últimos anos, o que é preocupante, considerando-se a sua reconhecida relevância e capacidade de gerar benefícios. Reforça-se, portanto, a necessidade de ampliar o investimento de recursos no programa, neste e nos próximos anos, de forma a se garantir que ele possa atingir as suas finalidades e atuar adequadamente no combate aos atuais desafios.

Palavras-chave: agricultura familiar; políticas públicas; segurança alimentar e nutricional.

\section{ABSTRACT}

Intended to encourage family farming and promote food and nutritional security, the Food Acquisition Program - PAA purchases products directly from family farmers and their organizations to attend population in situation of vulnerability through the do- 
nation of these foods. This study did a quantitative analysis of the implementation of PAA in the period from 2011 to 2018 , seeking, mainly, to identify factors related to the access of the municipalities to the program, in addition to analyzing its focalization and potentialities to assist in facing the challenges that arise nowadays. The results showed that the program benefited more than 450 thousand family farmers in the period, purchasing 2 million tons of food and reaching beneficiaries in about $83 \%$ of Brazilian municipalities. The probability of access was greater for municipalities with less economic development, less urban, with more family farmers and belonging to the North and Northeast regions, indicating that the program is being effective in its focalization in attending the poorest regions of rural development as a priority. These data corroborate the studies found in the literature that point to PAA as an important commercialization channel for family farming, capable of promoting increased income, productive inclusion and the dynamization of the local economy, in addition to contributing to food and nutritional security. Thus, it is believed that the program is a relevant tool to be used as an instrument to mitigate negative effects in the economic and social spheres generated by the current crises. However, there was a significant decrease in the resources applied in PAA in recent years, which is worrying, considering its recognized relevance and ability to generate benefits. Therefore, it reinforces the need to expand the investment of resources in the program, in this and in the coming years, in order to ensure that it can achieve its goals and act appropriately in the fight against current challenges.

Keywords: family agriculture; public policies; food security and nutrition. 


\section{INTRODUÇÃO}

O Programa de Aquisição de Alimentos (PAA) foi criado em 2003, por meio do art. 19 da Lei $\mathrm{n}^{\mathrm{o}}$ 10.696, com os objetivos centrais de incentivar e fortalecer a agricultura familiar e promover a segurança alimentar e nutricional (SAN) da população mais vulnerável, proporcionando o acesso a alimentos em quantidade, qualidade e regularidade adequados (Brasil, 2003). É um programa inserido no âmbito da Política Nacional de Segurança Alimentar e Nutricional (PNSAN) que atua também com a função de política de fomento agrícola, uma vez que promove a aquisição de produtos diretamente dos agricultores familiares e de suas organizaçóes, proporcionando para eles um canal de comercialização e promovendo a inclusão social no campo.

Estudos realizados em diferentes regióes do Brasil vêm mostrando diversos benefícios trazidos por este programa, evidenciando a sua contribuição para incentivar a produção de alimentos da agricultura familiar e melhorar a qualidade de vida dos seus beneficiários, fornecedores e consumidores. Além disso, observam-se também efeitos positivos do PAA na dinamização da economia local e na promoção da sustentabilidade da produção (Sambuichi et al., 2019a).

O Brasil enfrenta atualmente uma crise econômica que teve início em 2014, e se intensificou em 2015 e 2016, tendo como consequências o aumento do desemprego e da desigualdade econômica e social, a queda do consumo e a diminuição das atividades da indústria nacional. Além disso, a atual crise sanitária provocada pela Covid-19 está causando o encolhimento das economias em todo o mundo, o que tem agravado ainda mais o já fragilizado quadro econômico brasileiro. O PAA, por todas as peculiaridades de operacionalização e finalidades, bem como por sua natureza intersetorial, apresenta potencialidades para ser uma política pública relevante no enfrentamento dos problemas causados pelas crises atuais.

Este trabalho objetivou analisar a execução do PAA nos municípios brasileiros no período de 2011 a 2018, buscando identificar fatores relacionados ao acesso à política, além de analisar a sua focalização nos municípios que seriam mais indicados para receber os recursos, de acordo com os objetivos e prioridades estabelecidos para o programa. Além disso, foram analisadas as potencialidades do PAA para auxiliar no 
enfrentamento aos desafios que se apresentam na atualidade em decorrência da crise econômica e sanitária e seus reflexos sobre as economias locais, a produção de alimentos e a segurança alimentar da população.

Além desta introdução, o texto está dividido em outras cinco seçôes. A segunda seção traz uma revisão de literatura sobre o programa, incluindo a sua caracterização, público-alvo, benefícios, focalização e acesso. A terceira apresenta os métodos da pesquisa, descrevendo as fontes de dados e as ferramentas utilizadas na análise. Na sequência, tem-se a apresentaçáo dos resultados e discussóes das análises quantitativas. A quinta seção apresenta um panorama e perspectivas do PAA na atualidade; e, por fim, na sexta seção, são tecidas as consideraçốes finais.

\section{PROGRAMA DE AQUISIÇÃO DE ALIMENTOS (PAA)}

\subsection{Caracterização do programa}

O PAA foi instituído por meio da Lei no 10.696, de 2 de julho de 2003, a qual teve como objetivo principal dispor sobre a repactuação e o alongamento de dívidas de agricultores oriundas de operaçóes de crédito rural, visando reduzir os problemas de endividamento causados pelas operaçóes do Programa Nacional de Fortalecimento da Agricultura Familiar (Pronaf). Esta lei incluiu ainda, em seus dispositivos, outras providências com o propósito de apoiar os agricultores familiares, entre elas, a compra de alimentos da agricultura familiar com dispensa de licitação, instituindo assim, em seu art. 19, o PAA. O objetivo de promover a segurança alimentar e nutricional já estava previsto também no texto original da lei, o qual estabeleceu que as compras e doações deste programa seriam destinadas integralmente para o apoio às "açóes de combate à fome e promoção da segurança alimentar" (Brasil, 2003).

A regulamentação do programa foi feita por meio do Decreto $n^{\circ} 7.775$, instituído em 4 de julho de 2012. Este decreto definiu as referências básicas do PAA e estabeleceu as regras para o seu funcionamento. Foram definidas nove finalidades para o programa, estabelecendo-se assim outros objetivos além dos que estavam previstos na Lei no 12.512 , de 14 de outubro de 2011, a qual alterou a lei original (box 1). 
BOX 1

Finalidades do PAA estabelecidas no Decreto oㅜ 7.775/2012

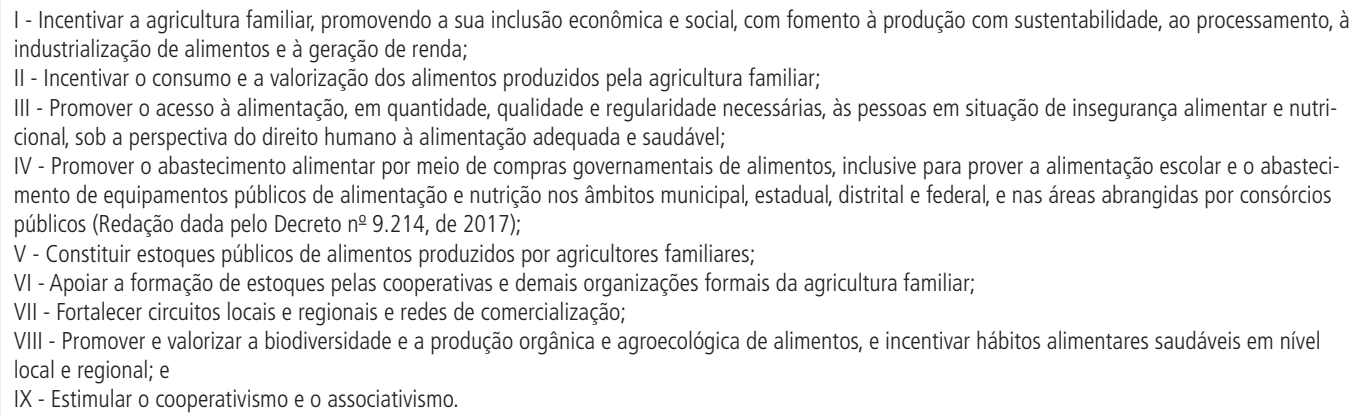

Conforme estabelecido no Decreto no 7.775/2012, o programa apresenta dois tipos de beneficiários: os fornecedores, grupo formado pelos agricultores familiares; e os consumidores, que são as pessoas em situação de insegurança alimentar e nutricional, compreendendo também aqueles atendidos pela rede socioassistencial, pelos equipamentos de alimentação e nutrição e pelas redes pública e filantrópica de ensino (Brasil, 2012). São priorizadas para atendimento as organizaçôes fornecedoras constituídas por mulheres, por povos e comunidades tradicionais e por outros grupos específicos.

Atualmente, ele é operado por meio de seis modalidades: i) Compra com Doação Simultânea (CDS); ii) Compra Direta (CDAF); iii) Apoio à Formação de Estoques; iv) Incentivo à Produçáo e ao Consumo de Leite - PAA Leite; $v$ ) Compra Institucional; e vi) Aquisição de Sementes. A principal modalidade de operação do programa é a CDS, a qual promove a aquisição de alimentos produzidos pelos agricultores familiares e os doa a organizaçóes sociais que atendem a pessoas inseridas em contextos de vulnerabilidade social e alimentar.

Para a gestão das açôes que envolvem os beneficiários e as diferentes modalidades, o PAA conta com o Grupo Gestor interministerial composto pelo Ministério da Cidadania - representado pela Secretaria Especial do Desenvolvimento Social -, Ministério da Agricultura, Pecuária e Abastecimento (Mapa) - representado principalmente pela Companhia Nacional de Abastecimento (Conab) -, Ministério da Economia e Ministério da Educação (Brasil, 2020). Os recursos são provenientes, em sua maior parte, do Ministério da Cidadania, podendo vir também do Mapa, que opera as modalidades Estoque e CDAF, ou do ente público da administraçáo direta ou indireta interessado na aquisição de alimentos, no caso da modalidade Compra Institucional. 
A execução do programa é feita por diferentes operadores, destacando-se, entre eles, a Conab, a qual teve papel importante na criação da política e foi historicamente a principal executora do PAA, atuando nas modalidades CDS, CDAF, Estoque e Sementes. Outros operadores são os estados, o Distrito Federal e os municípios, os quais participam atualmente na modalidade CDS via Termo de Adesão firmado diretamente com o Ministério da Cidadania, tipo de operaçáo cuja participação vem crescendo na execução do programa, em anos mais recentes (Sambuichi et al., 2019a). Os estados operam também a modalidade Leite, para compra e doação de leite em localidades da região semiárida do Nordeste e Sudeste. Na modalidade Compra Institucional, a operação é realizada diretamente pela instituição - federal, estadual ou municipal - interessada na compra. A principal diferença entre as compras realizadas pela Conab e via Termo de Adesão é que, no primeiro caso, o acesso ao programa só é feito por meio de organizaçóes de produtores (cooperativas e associaçóes), enquanto no segundo caso o contrato é firmado com o agricultor individualmente. Sendo assim, o Ministério da Cidadania destina os recursos aos agricultores diretamente via cartão bancário emitido pelo Banco do Brasil, via Termo de Adesão, ao passo que a Conab realiza pagamentos às cooperativas que participam do programa, as quais, por sua vez, destinam os recursos aos agricultores que entregaram os alimentos.

\subsection{Agricultura familiar, políticas públicas e PAA}

A agricultura familiar é uma categoria que se caracteriza principalmente pelo trabalho em pequenas unidades de produçáo e utilização de mão de obra predominantemente familiar. São produtores que, em geral, dirigem o seu próprio empreendimento e têm a maior parte da sua renda proveniente deste. É uma categoria composta por grupos heterogêneos que inclui camponeses, silvicultores, aquicultores, extrativistas, pescadores artesanais, indígenas, quilombolas e outros povos e comunidades tradicionais (Cavalcanti, Marjotta-Maistro e Araújo, 2018). No Brasil, a definição legal desta categoria está descrita na Lei no 11.326/2006, conhecida como Lei da Agricultura Familiar, e no Decreto no 9.064/2017, que a regulamenta.

Esse tipo de agricultura caracteriza-se, também, por apresentar uma ligação indissociável entre a família e o estabelecimento, constituindo assim a chamada unidade de produção familiar (UPF). As UPFs desempenham funções variadas de natureza econômica, ambiental, social e cultural, sendo elementos fundamentais para o desenvolvimento rural nas redes territoriais em que estão integradas. Em geral, os agricultores 
familiares gerenciam sistemas agrícolas diversificados e preservam os alimentos tradicionais, o que contribui para a garantia do Direito Humano à Alimentação Adequada (DHAA) e para a promoção da agrobiodiversidade global. Nesse sentido, a agricultura familiar tem um potencial único para aumentar a sustentabilidade da agricultura e dos sistemas agroalimentares. Por essas potencialidades, e no contexto da agenda dos Objetivos do Desenvolvimento Sustentável (ODS), a Assembleia-Geral da Organização das Naçōes Unidas (ONU) aprovou, em dezembro de 2017, a Década das Naçôes Unidas para Agricultura Familiar 2019-2028 (Graziano da Silva, 2019).

Diversos estudos foram publicados a fim de se evidenciar a importância da agricultura familiar para o contexto brasileiro, e apontam que se trata de um setor multifuncional, responsável tanto pela ocupação no meio rural e fornecimento de alimentos quanto pela manutenção de homens e mulheres no campo (Kageyama, Bergamasco e Oliveira, 2013; Veiga, 1995), desenvolvimento local e dinamismo econômico nos municípios (Froehlich e Schneider, 2013). Ao longo dos anos, a agricultura familiar passou por muitas mudanças e assumiu um papel estratégico no contexto nacional, na produção de matérias-primas, no abastecimento alimentar das populaçóes e na dinâmica do desenvolvimento rural (Balsadi, 2004).

No Censo Agropecuário de 2006, foram identificados cerca de 5,1 milhóes de estabelecimentos agropecuários no Brasil, sendo que, destes, 4,3 milhóes foram classificados como estabelecimentos familiares, o que representava $84,4 \%$ dos estabelecimentos agropecuários, correspondendo a $24,3 \%$ da área total (IBGE, 2006). O levantamento do Censo Agropecuário mais recente, de 2017, apontou cerca de 3,9 milhóes de estabelecimentos classificados como agricultura familiar, o que representa $77 \%$ dos estabelecimentos agropecuários do Brasil, correspondendo a 23\% da área de todos os estabelecimentos agropecuários. Além disso, os dados mostram que a agricultura familiar ocupa $67 \%$ de todo o pessoal ocupado em agropecuária no país, cerca de 10,1 milhões de pessoas. Esses produtores são responsáveis também por $23 \%$ do valor total da produção agropecuária, por $48 \%$ do valor da produção de café e banana, $80 \%$ da mandioca, $69 \%$ do abacaxi e $42 \%$ da produção do feijão (IBGE, 2019).

No âmbito das políticas públicas, a agenda de apoio à agricultura familiar surgiu a partir da década de 1990, com a criaçâo do Pronaf, considerado o primeiro programa de fomento do governo federal voltado especificamente para esse público. A sua criação, em 
1996, foi resultante de um conjunto de reivindicaçôes por parte de movimentos sociais, corpo acadêmico e integrantes da própria sociedade civil organizada, que demandaram açôes de incentivo à produção e à inserção produtiva dessa categoria (Grisa et al., 2011).

$\mathrm{Na}$ década seguinte, outras políticas importantes foram sendo implementadas, buscando suprir as necessidades desse público específico. Entre tais políticas, destaca-se o PAA, criado no âmbito das ações estruturantes do Programa Fome Zero, como resultado da convergência dessa agenda com a temática da segurança alimentar e nutricional (Grisa et al., 2010; Sambuichi et al., 2019a). Contribuiu para isso a recriação do Conselho Nacional de Segurança Alimentar e Nutricional (Consea), ${ }^{1}$ em 2003, que ampliou os debates acerca desses temas e passou a reconhecer o apoio à agricultura familiar como uma importante estratégia de SAN, visto que grande parte da pobreza e da fome se concentram no meio rural (Graziano da Silva, 2019).

\subsection{Importância e benefícios do PAA}

O PAA veio a suprir uma carência importante detectada entre os agricultores familiares: o acesso a mercados. Para isso, o programa vale-se de um mecanismo de dispensa de licitação que permite ao agricultor o acesso direto ao mercado de compras institucionais. Ao facilitar a aquisição e propiciar a doação dos alimentos, o PAA também passa a promover a estruturação de novos circuitos de abastecimento e de comercialização local, ligando agricultores familiares (produtores) a grupos sociais em situação de risco alimentar (consumidores), reforçando a segurança alimentar e nutricional das populaçóes urbanas e rurais, tanto em nível local como num espaço territorial mais abrangente, e fortalecendo as economias regionais (Schmitt, 2005).

Com isso, o PAA reforça uma das estratégias importantes de inserção nos mercados adotada pela agricultura familiar, que são os circuitos curtos de comercialização. Estes circuitos se caracterizam por estabelecer vínculos de comércio em nível de território, por meio de relação direta entre o produtor e o consumidor final, ao mesmo tempo em que se mantém e se preserva a cultura alimentar territorial. Os circuitos curtos de comercialização, além de serem uma resposta a oligopólios no mercado convencional, estabelece relação entre produção, consumo e sociedade (Macías, 2018).

1. 0 Conselho Nacional de Segurança Alimentar e Nutricional (Consea), instituído em 1993, recriado em 2003, foi retirado da estrutura ministerial, no dia 1ํ de janeiro de 2019, por meio da Medida Provisória (MP) ㄲo 870. 
Além disso, o PAA busca apoiar a organização dos agricultores e a sua estrutura de produção, por meio do estímulo ao cooperativismo e ao associativismo, o fomento ao processamento e à industrializaçáo de alimentos, e o fortalecimento dos circuitos locais e regionais e redes de comercialização, conforme se observa nas finalidades do programa explicitadas no texto do Decreto no $7.775 / 2012$.

O estudo realizado por Sambuichi et al. (2019a) fez uma extensa revisão de literatura sobre o programa e mostrou, com base em evidências empíricas levantadas nas pesquisas já publicadas, que o PAA tem conseguido atingir as principais finalidades para as quais foi criado. Segundo este levantamento:

em geral, a maioria dos estudos mostrou avaliação bastante positiva do programa, sendo constatados benefícios para os agricultores e os consumidores que contribuíram para o fortalecimento da agricultura familiar e a redução da Insan [insegurança alimentar e nutriciona], além de incentivar a produção sustentável, o cooperativismo, a agroindústria familiar e o desenvolvimento local. Essas evidências indicam que o PAA está conseguindo obter os resultados esperados em seu modelo lógico, o que corrobora as principais hipóteses em que se baseia o programa e mostra que os estímulos gerados por meio de suas aquisiçôes e doaçôes são adequados para atingir seus objetivos. Esses resultados reforçam a importância do PAA como programa estruturante no âmbito da PNSAN, tendo o potencial de gerar impactos positivos sobre a sustentabilidade da cadeia agroalimentar e promover o desenvolvimento rural inclusivo (Sambuichi et al., 2019a, p. 45).

De acordo com o trabalho realizado por Santos, Soares e Benavides (2015), o PAA atua como dinamizador da economia local, provocando ganhos de rentabilidade, redução do tempo de retorno do capital investido e melhoria nas variáveis de comercialização, como o preço e o número de produtos vendidos. Há ainda o efeito do programa na economia local do ponto de vista da geração de receita para as famílias. O estudo feito por Dias e Rocha (2015) indicou que as compras do PAA contribuíram de maneira significativa para o crescimento do produto interno bruto (PIB) per capita em municípios pesquisados no Rio Grande do Norte, estimando que um aumento de $1 \%$ das compras contribuiu para um crescimento do PIB per capita de aproximadamente $0,062 \%$.

Outro importante benefício destacado em vários estudos já realizados sobre o PAA é o estímulo à diversificação da produção. O estudo de Sambuichi et al. (2019b) com as compras realizadas pela modalidade CDS, no período de 2011 a 2018, constatou 
uma elevada diversidade de itens adquiridos nesta modalidade. Foi identificado um total de 536 diferentes produtos comprados no período, estimando-se uma média de 345 por ano. Além disso, esse estudo observou uma grande variedade de produtos frescos, in natura ou minimamente processados, incluindo principalmente frutas, verduras, legumes e carnes, e também itens da culinária regional e produtos da sociobiodiversidade, o que contribui para estimular hábitos alimentares saudáveis e preservar a cultura regional, os ecossistemas e a agrobiodiversidade.

Além dos benefícios gerados pelo PAA ao longo de seus dezessete anos, o programa também passou por um amadurecimento institucional e social, que provocou aprendizagem e readequaçóes de seus processos de implementação e a superação de algumas dificuldades. No entanto, estudos mais recentes vêm mostrando que, no momento em que a política se consolidou, houve um enfraquecimento de suas açôes, redução na distribuição orçamentária e perda de espaço na agenda pública, comprometendo a efetividade da política no nível local (Almeida, Perin e Sambuichi, 2019).

\subsection{Focalização e acesso ao programa}

Para atender às finalidades previstas no Decreto no 7.775/2012, o PAA tem como beneficiários prioritários os agricultores de baixa renda e as pessoas em situação de risco alimentar. $\mathrm{O}$ decreto inclui também como público prioritário as mulheres, povos $\mathrm{e}$ comunidades tradicionais e assentados da reforma agrária, como forma de promover a inclusão produtiva desses segmentos geralmente mais marginalizados no setor produtivo e/ou vulneráveis à insegurança alimentar e nutricional. Portanto, para cumprir plenamente suas finalidades, o programa deveria ser acessado prioritariamente nas regiốes mais carentes de desenvolvimento rural, onde houvesse mais necessidade de fortalecer as redes e organizaçôes da agricultura familiar e promover a segurança alimentar da população.

Visando analisar o grau de cobertura e a focalização do PAA no estado de Minas Gerais, Simão, Silva e Silveira (2014) criaram um Índice de Propensão à Execução do PAA (IPE-PAA), com base nas compras operadas no ano de 2011 pela Conab e pelos municípios. Eles constataram que $27 \%$ (228) dos municípios do estado participaram do programa em 2011, sendo que, nestes, a taxa de focalizaçáo foi de 69,2\% (158), demonstrando que grande parte dos beneficiários do PAA se encontra em municípios em que há demanda. Porém, apesar de a maioria 
dos recursos terem sido repassados a agricultores dos municípios de maior demanda das açóes do programa, a taxa de cobertura nessas regiôes ainda se mostrava incipiente, tendo em vista suas necessidades.

A eficácia da focalização e cobertura do PAA foi medida também por Salgado $e t$ al. (2017), em um estudo com abrangência nacional que envolveu a elaboração de dois indicadores que representaram o "Risco de insegurança alimentar" e a "Necessidade de acesso ao mercado dos agricultores familiares". De acordo com esses indicadores, o PAA seria mais demandado em municípios com maior presença de agricultores familiares, baixo dinamismo econômico e alto risco de insegurança alimentar, localizados nas regióes Nordeste e Norte, que concentram grande parte da extrema pobreza rural. Os autores estimaram haver uma taxa de focalizaçáo de $58 \%$ nos municípios de maior demanda, corroborando análises anteriores, as quais indicaram que a maioria dos agricultores familiares e da população em situação de insegurança alimentar e nutricional, beneficiados pelo PAA, estão em municípios que apresentam demanda real de suas açóes. No entanto, quando se analisou o nível de cobertura, foi constatado que os municípios com menor demanda tinham as maiores taxas de cobertura, ou seja, estavam recebendo uma parte considerável dos recursos do programa, apesar de apresentarem menor propensão de execução, enquanto algumas regióes, como o Norte e o Nordeste, não estavam tendo a prioridade que deveriam ter.

Santos et al. (2015) estudaram os efeitos da densidade populacional e da proximidade de aglomerados urbanos sobre o nível de efetividade do PAA, utilizando dados de compras do programa realizadas no ano de 2011. O estudo identificou uma correlação significativa entre as concentraçóes populacionais e os registros de agricultores vinculados ao PAA, principalmente nas regióes metropolitanas. Os autores explicaram o fato tanto pela "existência de agriculturas diversificadas, os chamados cinturôes verdes, quanto pela demanda para compras institucionais gerada pela concentração de pessoas em vulnerabilidade social presentes nos grandes centros urbanos" (Santos et al. 2015, p.1).

Diversos fatores podem influenciar a capacidade de agricultores e municípios acessarem o programa. A pesquisa de Barth-Teixeira et al. (2017), que analisou essencialmente o PAA/Conab no Território da Cidadania Cantuquiriguaçu-PR, composto por vinte municípios, concluiu que os municípios mais eficientes e que obtiveram 
melhores resultados na captação de recursos foram também aqueles que apresentaram melhores condiçóes de organização da produção e, principalmente, maior mobilizaçáo e organização dos agricultores familiares e das entidades beneficiárias.

Outra variável que pode influenciar o acesso de municípios ao PAA é o desconhecimento do funcionamento da política por parte dos gestores públicos que, ao temerem as leis de Responsabilidade Fiscal e de Transparência, acabam optando por não firmar o Termo de Adesão com a esfera federal (Almeida, 2014). As mudanças de governos também podem modificar ou interromper o fluxo de execução do PAA. Ao término das propostas com os municípios ou estados, os gestores deixam de enviar novos projetos por questóes de incompatibilidade de agenda política da gestáo, insegurança dos novos gestores em assumir todas as responsabilidades acordadas em gestôes anteriores ou equipes novas não habituadas aos procedimentos e processos do PAA (Chmiekewska, Souza e Lourete, 2010). Este fenômeno foi observado com o Programa Mais Gestão, cujo objetivo era ampliar o acesso de cooperativas da agricultura familiar às políticas públicas, como o PAA, por meio de assistência técnica e extensão rural, e em que, com o processo de mudança de governo, houve interrupção na política para agricultores familiares, que deixaram de ser assistidos (Sousa, 2018).

Além disso, há problemas com a inexistência de recursos humanos aptos para a elaboração de propostas, manuseio de sistemas de informação específicos para a execução da política (Almeida, 2014), ou ainda para cadastramentos ou exigências burocráticas mínimas, como os documentos exigidos para a implementação do PAA (Martins, 2013). Em Minas Gerais, o diagnóstico foi de que o programa contava com ajuda de um número excessivo de voluntários, o que evidencia a insuficiência de recursos humanos para conduzi-lo. Isso, no longo prazo, prejudica a continuidade da política (Brasil, 2011).

Entre os gargalos observados para a implementação do programa pelos governos municipais, observa-se que as prefeituras locais lidam com problemas orçamentários graves, sendo que muitas apresentam como principal (ou única) fonte de receita os repasses do Fundo Constitucional de Participação dos Municípios (FPM). Adicionalmente, embora o termo de adesão não preveja contrapartida financeira dos estados e municípios, os custos e investimentos na execução do programa devem estar previstos no planejamento orçamentário dos entes, o que exige do nível local, principalmente 
da parte dos municípios, que este disponha de orçamento suficiente para cumprir as necessidades relacionadas à infraestrutura básica para logística, armazenamento e transporte (Chmiekewska, Souza e Lourete, 2010; Martins, 2013; Almeida, 2014).

O estudo realizado pela Secretaria de Avaliação e Gestão da Informação do Ministério do Desenvolvimento Social e Combate à Fome (Atual Ministério da Cidadania), o qual objetivou fazer uma análise comparativa das famílias dos beneficiários consumidores do PAA-Leite com famílias não atendidas pelo programa em municípios do estado de Minas Gerais, constatou que, entre outras coisas, as estruturas para centros de distribuição eram cedidas, em parte, pela própria comunidade, e compartilhados com outras entidades, de naturezas distintas. Muitas destas estruturas eram inadequadas para a execução de atividades do PAA-Leite, sem os equipamentos necessários para armazenamento e distribuição (Brasil, 2011).

Independentemente da modalidade de acesso, a literatura que aborda os desafios e dificuldades nos modelos e processos de implementaçáo do PAA têm apontado que a formação de redes, participaçáo e controle social, organização produtiva, bem como capacidade institucional, são elementos relevantes e que influenciam o maior ou menor acesso ao programa, bem como o sucesso de implementaçáo (Neto e Hespanhol, 2018).

O estudo realizado por Veloso (2017), que analisou os mercados institucionais de municípios do oeste de São Paulo, concluiu que a capacidade de formação de redes locais que sejam capazes de manifestar as demandas locais induz o acesso e dá subsídios para o bom funcionamento de políticas públicas como o PAA. Especificamente no município de Irapuru, um fator central que contribuiu para o baixo número de projetos aprovados pelo PAA, entre 2010 e 2016, foi justamente a dificuldade de atuação em rede. $\mathrm{O}$ autor identificou também que:

quando os agentes locais e sujeitos se articulam, mesmo que tenham conflitos e divergências entre eles, o PAA e o PNAE têm resultados mais satisfatórios, beneficiando não apenas os componentes da rede, mas extrapolando para o comércio local e instituiçôes de outros municípios. Contudo, quando as ações são desarticuladas ou desconexas, a informação não circula e as dificuldades aparecem, e, consequentemente, os programas têm descontinuidade ou sofrem interrupçóes (Veloso, 2017, p. 191). 
Em Tapes, no Rio Grande do Sul, o estudo de Froehlich e Schneider (2013) identificou que a integraçáo ou a atuação em rede de gestores, produtores, consumidores e demais atores sociais envolvidos na implementação da política são decisivos para a execução, adequaçôes e superaçóes de dificuldades que envolvem a implementação do PAA.

Seguindo nesta mesma linha, Silva e Schmitt (2012) concluíram, no estudo realizado na Bahia e no Rio Grande do Sul, que a atuação em redes ou por meio de organizaçôes da sociedade civil para execução do PAA tem efeitos diretos na participação e no controle social. Isso porque, além de elas serem as reivindicadoras de políticas públicas, como o PAA, o programa acaba estimulando a cooperação e integração entre os agentes envolvidos, além de acontecer um processo de transferência de responsabilidades para as próprias organizaçóes sociais. As relaçóes previamente construídas entre os agentes sociais - associaçôes, cooperativas, gestores e técnicos públicos, organizações não governamentais (ONGs) e movimentos sociais - foram as principais responsáveis, nas áreas estudadas pelos autores, pela maior capilaridade do PAA.

Embora o PAA fomente a articulação entre os atores sociais, a participação social ainda é incipiente, e parece haver, por parte do Estado, dificuldades de serem construídas ferramentas de participação e controle social diante da realidade da maioria dos municípios brasileiros. De acordo com Hespanhol (2007), no texto Agricultura, desenvolvimento e sustentabilidade, citado por Neto e Hespanhol (2018), a dificuldade na implementação de políticas públicas está na dispersão populacional, heterogeneidade inter e intrarregionais, baixo nível de acesso aos serviços públicos básicos e pouca organização da administração pública municipal.

Outras questóes também são determinantes para viabilizar o acesso ao programa. Grisa et al. (2010) afirmam que, por mais variada que seja a logística do PAA, as questóes relacionadas à infraestrutura, sobretudo ao transporte, serão sempre fatores fundamentais para a continuidade da política - no caso dos transportes, há problemas relacionados à falta de veículos, precarização de estradas e rodovias e dificuldades de acesso por vias fluviais em determinadas regiôes do Brasil. O estudo realizado por Almeida (2014) analisou a relação entre implementação do PAA e a capacidade institucional em Gravataí-RS, identificando que os gargalos se relacionam principalmente às questôes de infraestrutura básica, orçamentárias e de recursos humanos. Além disso, a autora apontou que, embora os gestores públicos locais devessem fomentar a participação de grupos sociais, 
em vez de atuar de modo individualizado, na prática, não é exatamente o que ocorre. Há conflitos político-partidários que acabam influenciando negativamente no processo de participação e controle social na execução do PAA.

\section{MÉTODOS}

Neste estudo, foi aplicada uma metodologia de análise quantitativa de dados secundários, abrangendo análise descritiva e regressão binomial logística. As bases de dados utilizadas foram microdados provenientes de registros administrativos de compras e doações do PAA, disponibilizados para esta pesquisa pelo Ministério de Cidadania e pela Conab. Essas bases abrangeram as doaçóes de alimentos realizadas na modalidade CDS e todas as compras do programa executadas no período de 2011 a 2018, em todo o Brasil, nas suas diferentes modalidades, operadores e fontes de recursos, com exceção da modalidade Compra Institucional, a qual é operada pelo ente interessado e para a qual não existem ainda dados sistematizados disponíveis.

A análise descritiva considerou os montantes de recursos aplicados em compras, ${ }^{2}$ as quantidades de alimentos (em kg) e o número de agricultores atendidos, nas diferentes modalidades do programa, considerando os recortes territoriais de grande região, UF e município, com ênfase no recorte municipal. Para a realização dessas análises, foi considerado o município do agricultor que forneceu o produto, informação identificada por meio do cruzamento da base do PAA com a base da Declaração de Aptidão ao Pronaf ${ }^{3}$ (DAP), disponibilizada para esta pesquisa pela Secretaria de Agricultura Familiar (SAF/Mapa). Além disso, foi realizada ainda uma análise dos municípios que receberam doaçóes de alimentos do programa, considerando-se o município da entidade que recebeu as doaçóes, com informaçóes obtidas da base de microdados do PAA.

Foi realizada também uma análise descritiva das propostas de compra, estimando-se o número de propostas e os valores médios aplicados, número médio de agricultores e municípios abrangidos por proposta de compra, para as operações feitas pela Conab e pelos estados e municípios via Termo de Adesão. Esta análise não foi feita

2. Valores corrigidos anualmente pela inflação para 2018 pelo IPCA-E, mês base dezembro.

3. Cadastro que permite 0 acesso do agricultor familiar às políticas públicas direcionadas a este segmento. 
para as compras realizadas nas modalidades Leite e Compra Institucional e as compras operadas por convênios na modalidade CDS, por não dispormos de microdados com identificação da proposta para estes casos específicos.

Para analisar os fatores relacionados ao acesso dos municípios ao programa e a sua focalização, foi realizada uma regressão binomial logística relacionando o acesso ao programa com as diversas variáveis explicativas que constam na tabela 1. Entre os aspectos que foram considerados no modelo, estáo o desempenho econômico, o tamanho da população, o número de agricultores familiares aptos a acessar a política, o grau de urbanização, a proximidade a grandes centros urbanos e a região à qual pertence o município.

TABELA 1

Descrição das variáveis utilizadas no modelo de acesso dos municípios ao PAA ${ }^{1}$

\begin{tabular}{llrrrr}
\hline Aspecto analisado & Variável & Máximo & Mínimo & Média & Desvio \\
\hline Desempenho econômico & Índice Firjan de Desenvolvimento Municipal (IFDM), Área de & 0,85 & 0,25 & 0,51 & 0,11 \\
& Emprego e Renda & 7,07 & 2,91 & 4,11 & 0,50 \\
Tamanho da população & Logaritmo do tamanho populacional do município & 100 & 0 & 4,68 & 13,60 \\
Grau de urbanização & Percentual de área urbana & 5.265 & 0 & 314,6 & 452,2 \\
Número de agricultores aptos & Número de estabelecimentos que possuem DAP (Censo 2017) & 1 & 0 & 0,21 & 0,41 \\
Proximidade a grandes centros & Se o município pertence a uma região metropolitana (dummy) & 1 & 0 & 0,09 & 0,28 \\
& Região Norte (dummy) & 1 & 0 & 0,33 & 0,47 \\
& Região Nordeste (dummy) & 1 & 0 & 0,28 & 0,45 \\
Região à qual pertence & Região Sudeste (dummy) & 1 & 0 & 0,21 & 0,41 \\
& Região Sul (dummy) & 1 & 0 & 0,08 & 0,28 \\
\hline
\end{tabular}

Fonte: Dados da pesquisa.

Elaboração dos autores.

Nota: ${ }^{\prime} \mathrm{n}=4.971$ municípios.

Como uma proxy do desempenho econômico, foi utilizado o Índice Firjan de Desenvolvimento Municipal (IFDM) para a área de emprego e renda, o qual é calculado anualmente com base em estatísticas públicas oficiais disponibilizadas pelo extinto Ministério do Trabalho e Emprego (Firjan, 2020). O valor usado no modelo foi a média do índice calculado para os anos de 2011 a 2016, visto que a estatística ainda não está disponível para os anos de 2017 e 2018.

No caso do tamanho da população, para um melhor ajuste da variável, foi utilizado no modelo logaritmo natural da média da população estimada para o município para os anos de 2011 a 2018 (IBGE, 2020). Como estimativa do número de 
agricultores aptos a acessar o programa, utilizou-se o número de estabelecimentos agropecuários cujos produtores declararam estar cadastrados na base da DAP no Censo Agropecuário de 2017 (IBGE, 2019).

O grau de urbanizaçáo foi medido pelo percentual de área urbana do município, baseado na classificação de setores censitários adotada pelo Instituto Brasileiro de Geografia e Estatística (IBGE). A fim de se estimar a proximidade a grandes centros urbanos, foi criada uma dummy para identificar se o município pertence ou não a uma região metropolitana ( 0 = não pertence; 1 = pertence), baseada na relação de municípios integrantes de regióes metropolitanas fornecida pelo IBGE. O pertencimento às grandes regióes brasileiras foi identificado por meio de variáveis dummy, sendo que, como o modelo utilizado incluiu um intercept, a variável relativa à região Centro-Oeste foi omitida na regressão, para evitar colinearidade.

A análise de regressão considerou os municípios que mais acessaram o programa, definidos como aqueles que tiveram pelo menos cinco agricultores atendidos e $\mathrm{R} \$ 10$ mil recebidos no total do período, sendo estes comparados com os municípios que não tiveram nenhum acesso ao programa. Dos 5.570 municípios brasileiros, sete foram excluídos da análise, por não terem dados disponíveis para as variáveis percentual de área urbana e/ou IFDM emprego e renda, e 592 foram excluídos por terem tido acesso ao PAA abaixo dos limites mínimos estabelecidos, resultando em um número final de 4.971 municípios, sendo 3.855 os que acessaram (tratamento) e 1.116 os que não acessaram (controle). A análise foi realizada com uso do programa $\mathrm{R}$, função "glm", modelo binomial.

\section{RESULTADOS E DISCUSSÃO}

Os resultados e a discussão das análises quantitativas estão organizados em cinco subtópicos: i) análises descritivas gerais das compras do PAA no Brasil e regióes; ii) execução das compras nos municípios; iii) caracterização dos municípios que forneceram para o programa; iv) análise do acesso às doaçôes de alimentos da modalidade Compra com Doação Simultânea; e $v$ ) análise binomial logística do acesso dos municípios ao programa - município do agricultor. 


\subsection{Análises descritivas gerais das compras do PAA no Brasil e regiões}

No período de 2011 a 2018, foram aplicados mais de R 5 bilhóes em compras do programa, ${ }^{4}$ correspondendo a cerca de 2 milhóes de toneladas de produtos, adquiridos de quase 455 mil agricultores, abrangendo 79,9\% dos municípios brasileiros (tabela 2).

A maior parte das compras foi executada na modalidade CDS, a qual executou cerca de $\mathrm{R} \$ 3,5$ bilhóes (68,3\% do valor total aplicado), beneficiando 358 mil agricultores (78,8\% dos beneficiários fornecedores atendidos), com acesso em mais de $74 \%$ dos municípios brasileiros (tabela 2). A modalidade Leite também se destacou, com mais de R \$ 1 bilhão em compras (20,4\%), porém, com uma abrangência geográfica bem mais restrita, visto que tal modalidade é executada apenas na região semiárida do Nordeste e Sudeste.

\section{TABELA 2}

Execução do PAA por modalidade, valor total aplicado em compras, quantidades de alimentos adquiridos, número de agricultores atendidos, número de municípios que acessou o programa e percentual de acesso dos municípios ao programa (2011-2018)

\begin{tabular}{|c|c|c|c|c|c|}
\hline Modalidade & $\begin{array}{l}\text { Valor aplicado' } \\
\text { (R\$ milhões) }\end{array}$ & $\begin{array}{c}\text { Quantidades } \\
\text { (1 mil toneladas) }\end{array}$ & $\begin{array}{c}\text { № de agricultores² } \\
\text { (milhares) }\end{array}$ & № de municípios 3 & Acesso (\%) \\
\hline CDAF & 227,1 & 43,9 & 20,6 & 601 & 10,8 \\
\hline CDS & $3.548,0$ & $1.299,7$ & 358,2 & 4150 & 74,5 \\
\hline Estoque & 332,1 & 53,4 & 32,1 & 997 & 17,9 \\
\hline Leite & $1.060,0$ & 722,8 & 66,6 & 960 & 17,2 \\
\hline Sementes ${ }^{4}$ & 28,4 & 5,7 & 1,5 & 126 & 2,3 \\
\hline Todas as modalidades & $5.195,6$ & $2.125,5$ & 454,8 & 4451 & 79,9 \\
\hline
\end{tabular}

Fonte: Dados da pesquisa.

Elaboração dos autores.

Notas: 1 Valores corrigidos para dezembro de 2018 pelo IPCA-E.

${ }^{2}$ Número de agricultores quantificado para o total do período, sem repetição entre os anos e entre as modalidades.

${ }^{3}$ Municípios que apresentaram pelo menos um agricultor que forneceu produtos para o programa; o número é apresentado para o total do período, sem repetição. ${ }_{4}^{4}$ Para a modalidade Sementes, os valores apresentados correspondem ao período 2015-2018, pois, antes de 2015, as compras de sementes eram realizadas por meio da modalidade CDS.

4. Em valores corrigidos anualmente pelo IPCA-E para dezembro de 2018. 
Esses resultados evidenciaram, como já observado também em outros estudos, a participaçáo predominante da modalidade CDS na execução do PAA (Sambuichi et al., 2019a). Observou-se que, além de apresentar os maiores valores de compras, quantidades de alimentos adquiridos e número de agricultores beneficiados, esta é também a modalidade com maior abrangência territorial, tendo sido acessada por um elevado número de municípios em todas as regióes.

A literatura sobre o PAA aponta também outros destaques para esta modalidade. Ela é considerada a principal inovação do programa, por conciliar diferentes instrumentos de política pública, atendendo concomitantemente às finalidades de fomento agrícola, por meio da compra de alimentos da agricultura familiar, e de promoção da segurança alimentar e nutricional de populaçôes vulneráveis, por meio da doação a entidades que fazem a sua distribuição (Sambuichi et al., 2019a). Esta modalidade contribui também para um dos principais benefícios apontado para o PAA, que é o estímulo à diversificação da produção, devido à elevada variedade de itens adquiridos (Sambuichi et al. 2019b).

Outra modalidade que se destacou foi o PAA-Leite, a qual, apesar de ter uma abrangência territorial restrita à região semiárida, executou mais de $20 \%$ do total de recursos aplicados no PAA no período. Esta modalidade também concilia os instrumentos de compra e doação de alimentos, com a dupla funçáo de beneficiar fornecedores e consumidores; porém, compra uma diversidade menor de produtos, restringindo-se a leite de vaca ou cabra in natura. Tem uma função importante, por atuar em territórios que apresentam elevados índices de pobreza, atendendo a populações muito vulneráveis à insegurança alimentar e nutricional.

A maior quantidade de compras ocorreu na região Nordeste, onde foram executados cerca de $\mathrm{R} \$ 2,3$ bilhôes, beneficiando aproximadamente 213 mil agricultores em 1.607 municípios. O maior percentual de acesso ao programa ocorreu, porém, na regiâo Sul, onde observou-se o acesso de beneficiários fornecedores em 90,6\% dos municípios. A região Centro-Oeste apresentou os menores valores de compras, e a região Sudeste, o menor percentual de acesso dos municípios (tabela 3). 
TABELA 3

Execução do PAA no Brasil e regiões: valor total aplicado em compras, quantidades de alimentos adquiridos, número de agricultores atendidos, número de municípios que acessou o programa e percentual de acesso dos municípios ao programa (2011-2018)

\begin{tabular}{|c|c|c|c|c|c|}
\hline Região & $\begin{array}{l}\text { Valor aplicado' } \\
\text { (R\$ milhões) }\end{array}$ & $\begin{array}{l}\text { Quantidades } \\
\text { (1 mil toneladas) }\end{array}$ & $\begin{array}{c}\text { № de agricultores² } \\
\text { (milhares) }\end{array}$ & № de municípios ${ }^{3}$ & Acesso (\%) \\
\hline Norte & 497,7 & 165,5 & 46,0 & 407 & 90,4 \\
\hline Nordeste & $2.305,8$ & $1.024,3$ & 213,2 & 1.607 & 89,6 \\
\hline Sudeste & $1.173,6$ & 561,7 & 89,4 & 1.055 & 63,2 \\
\hline Sul & 932,8 & 279,6 & 81,8 & 1.079 & 90,6 \\
\hline Centro-Oeste & 285,7 & 94,4 & 24,4 & 303 & 64,9 \\
\hline Brasil & $5.195,6$ & $2.125,5$ & 454,8 & 4.451 & 79,9 \\
\hline
\end{tabular}

O destaque observado para o Nordeste já seria esperado, por ser a região que apresenta maior quantidade de agricultores familiares. Segundo o Censo Agropecuário 2017, quase metade dos estabelecimentos (47\%) que pertencem à agricultura familiar se localizam nessa região (IBGE, 2019). Além disso, a predominância das regiôes Nordeste e Sudeste, em valor total de compras e quantidade de alimentos adquiridos, foi muito influenciada também pelo fato de a modalidade Leite ter atuação restrita nessas regióes, embora o Nordeste tenha se destacado em todas as modalidades.

O elevado percentual de acesso na regiáo Sul se explica pelo fato de a agricultura familiar se apresentar mais organizada nesta região, o que facilita mais o acesso ao programa, especialmente nas modalidades operadas pela Conab. Em valores percentuais, porém, o destaque foi para a regiáo Norte, onde cerca de $90 \%$ dos municípios acessaram o PAA, sendo também esta a única regiấo onde o acesso aumentou nos últimos anos. A região de menor execução do programa foi o Centro-Oeste, o que já seria esperado, pois, apesar de a agricultura familiar representar $64,3 \%$ dos estabelecimentos desta região, ela concentra apenas $5,7 \%$ do total dos estabelecimentos agropecuários pertencentes à agricultura familiar no Brasil (IBGE, 2019). 
O programa beneficiou agricultores em todos os estados da Federação e, também, no Distrito Federal. Os maiores percentuais de acesso foram observados nos estados do Acre, Amapá, Rondônia, Roraima e Tocantins, os quais tiveram todos os seus municípios acessando o PAA em pelo menos um ano durante o período de 2011-2018 (figura 1).

\section{FIGURA 1}

Percentual de municípios que acessaram o PAA, por estado (2011-2018)

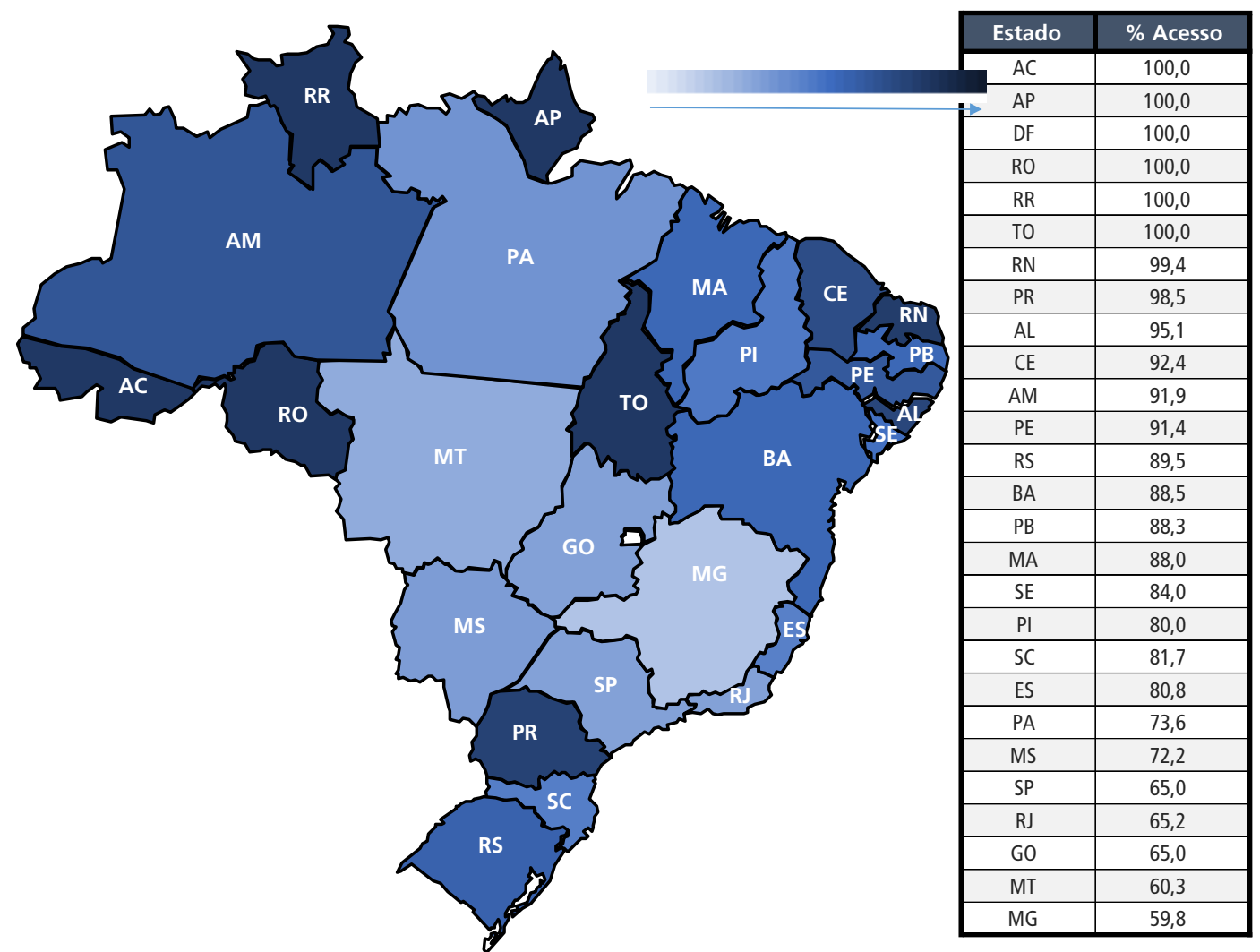

Fonte: Dados da pesquisa.

Analisando-se a evolução das compras no período, observa-se que os maiores valores foram executados em 2012 (tabela 4). Em 2013, houve uma queda acentuada nas compras do programa, com uma reduçáo de quase $50 \%$ dos valores executados. Após uma recuperação parcial em 2014, a tendência de queda continuou ao longo do período, tendo sido executado, em 2018, cerca de apenas um quinto do valor observado em 2012. 
TABELA 4

Execução do PAA por ano: valor total aplicado em compras, quantidades de alimentos adquiridos, número de agricultores atendidos, número de municípios que acessaram o programa e percentual de acesso dos municípios ao programa (2011-2018)

\begin{tabular}{|c|c|c|c|c|c|}
\hline Período & $\begin{array}{l}\text { Valor aplicado' } \\
\text { (R\$ milhões) }\end{array}$ & $\begin{array}{l}\text { Quantidades } \\
\text { (1 mil toneladas) }\end{array}$ & $\begin{array}{c}\text { № de agricultores } \\
\text { (milhares) }\end{array}$ & № de municípios² & Acesso (\%) \\
\hline 2011 & $1.006,8$ & 465,4 & 156,6 & 3.207 & 57,6 \\
\hline 2012 & $1.157,1$ & 468,9 & 175,8 & 3.464 & 62,2 \\
\hline 2013 & 588,6 & 253,9 & 93,4 & 2.472 & 44,4 \\
\hline 2014 & 752,6 & 309,9 & 112,0 & 2.932 & 52,6 \\
\hline 2015 & 668,6 & 239,3 & 96,7 & 2.568 & 46,1 \\
\hline 2016 & 426,6 & 150,8 & 77,3 & 2.336 & 41,9 \\
\hline 2017 & 362,6 & 143,6 & 68,2 & 2.389 & 42,9 \\
\hline 2018 & 232,7 & 93,8 & 53,6 & 2.135 & 38,3 \\
\hline $2011-2018^{3}$ & $5.195,6$ & $2.125,5$ & 454,8 & 4.451 & 79,9 \\
\hline
\end{tabular}

Fonte: Dados da pesquisa

Elaboração dos autores.

Notas: ' Valores corrigidos para dezembro de 2018 pelo IPCA-E.

${ }^{2}$ Municípios que apresentaram pelo menos um agricultor que forneceu produtos para o programa.

${ }^{3}$ Os totais de agricultores e municípios são apresentados para o total do período, sem repetição.

A expressiva queda observada em 2013 é atribuída principalmente à operação da Polícia Federal (PF) que ficou conhecida como "Agro-Fantasma", deflagrada para apurar supostas irregularidades na execução das compras do programa pela Conab, no estado do Paraná. Conforme explica Sambuichi et al. (2019a), a partir desta operação, "várias recomendaçôes foram feitas para mudar os procedimentos adotados na aprovaçáo e acompanhamento dos projetos, o que, do ponto de vista das organizaçôes dos agricultores, resultou em mais burocracia e dificuldade de acesso ao programa”. Isto impactou significativamente a execução do PAA no Brasil, em especial as compras realizadas pela Conab na regiáo Sul, causando uma "desmobilizaçáo e recuo das estruturas físicas e sociais que haviam sido construídas anteriormente naquela região em função do programa”. Este impacto, porém, não foi observado no PAA executado pelos estados e municípios, cujos valores continuaram a crescer até 2016, quando o programa passou a sofrer cortes orçamentários, em razão da crise econômica e do ajuste fiscal nas contas públicas do governo federal. Com essas mudanças, porém, a Conab, que antes era a principal operadora do programa, passou a executar, no final do período, uma quantidade menor de compras que os demais operadores (Sambuichi et al., 2019a). 
O percentual de acesso dos municípios ao programa mostrou também, no geral, uma tendência de queda, com exceçáo dos picos de crescimento observados nos anos de 2012 e 2014. Essa tendência, porém, não foi observada em todas as regiōes. No Nordeste, o percentual de acesso tendeu a ficar mais estável, enquanto no Norte se observou uma tendência de aumento do acesso dos municípios, principalmente nos anos mais recentes (gráfico 1).

GRÁFICO 1

Percentual de municípios que acessaram o PAA, por região (2011-2018) (Em \%)

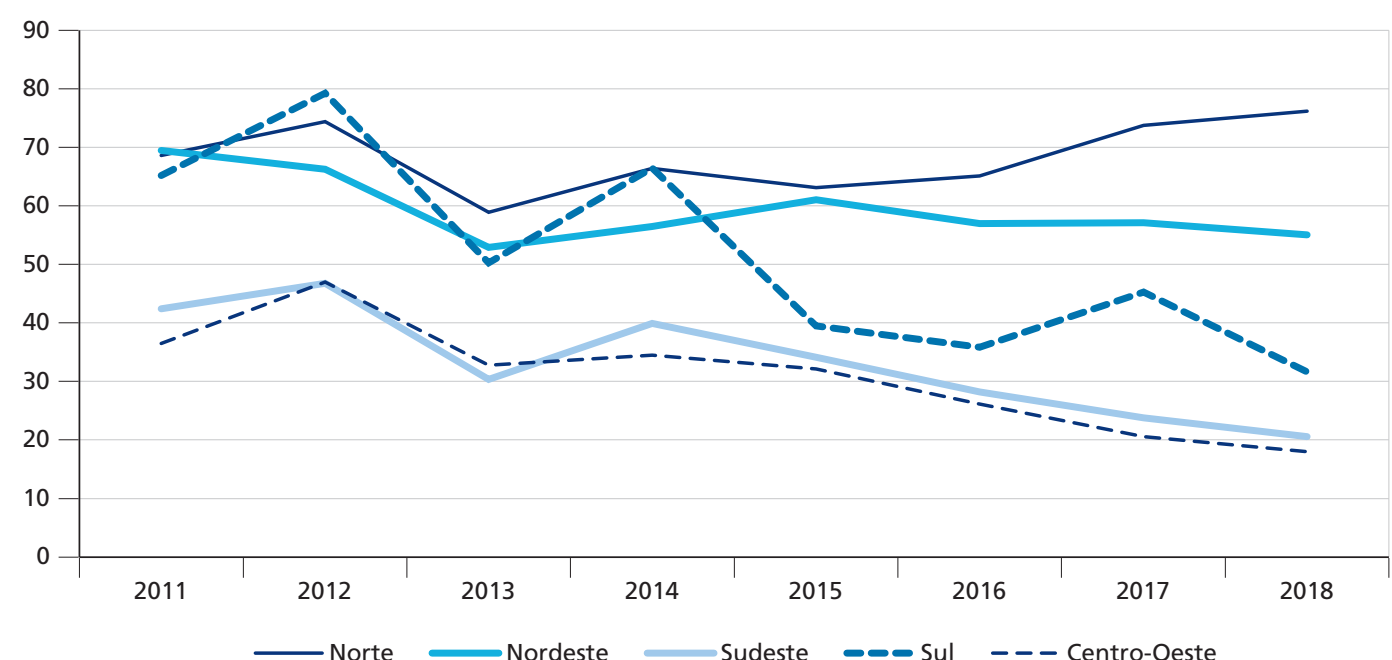

Fonte: Dados da pesquisa. Elaboração dos autores.

Quanto ao número de anos de acesso dos municípios ao programa, observa-se que, no geral, houve uma tendência de os municípios acessarem ao programa por um maior número de anos. Esta tendência, porém, não ocorreu em todas as regiôes. Enquanto nas regióes Norte e Nordeste observaram-se percentuais mais altos de municípios que acessaram o programa nos oito anos do período (39\% e $27 \%$, respectivamente), nas regiôes Centro-Oeste e Sudeste, os percentuais mais elevados foram apresentados pelos municípios que acessaram o PAA por apenas um ano $(18 \%$ e $17 \%$, respectivamente) (gráfico 2). Isto mostra que, em geral, os municípios destas últimas regióes tenderam a acessar o programa por menos anos no período. 
GRÁFICO 2

Percentual de municípios por número de anos de acesso - Brasil e regiões (2011-2018) (Em \%)

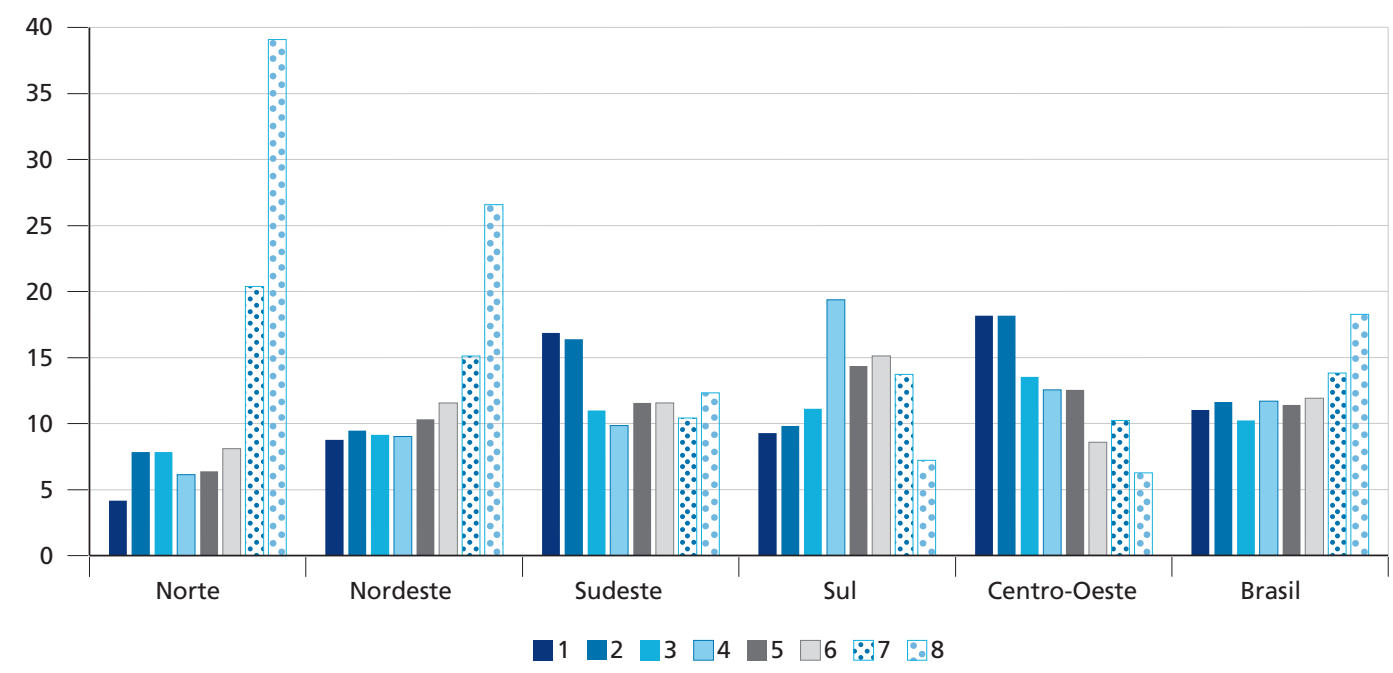

Fonte: Dados da pesquisa.

Comparando-se estes resultados com o estudo realizado por Salgado et al. (2017), o qual analisou a focalizaçáo e a cobertura do PAA com base nas compras de 2013, observa-se que o percentual de acesso quantificado naquele estudo foi menor. Os autores estimaram um acesso de apenas 20\% (1.089) dos municípios brasileiros ao programa, valor bem menor que o acesso de $44 \%$ estimado para aquele mesmo ano, no presente estudo. Isso explica-se, provavelmente, por eles terem utilizado dados extraídos do PAA Data, ${ }^{5}$ o qual apresenta principalmente dados relativos ao município da proposta, e não exatamente do agricultor. Conforme será analisado na sequência, uma mesma proposta de compra pode abranger agricultores de diferentes municípios, sendo que a análise por município da proposta indicaria um menor acesso ao programa do que a análise por município do agricultor. Além disso, é preciso considerar que 2013 foi um ano atípico, no qual houve uma elevada queda nos recursos aplicados, portanto, o nível de cobertura observado naquele estudo não corresponde ao alcance real do programa ao longo do seu período de existência.

5. Plataforma de informações sobre o PAA disponibilizada pelo Ministério da Cidadania. Disponível em: <https://bit. Iy/337AUXN>. 
Apesar dessas limitaçóes, o estudo de Salgado et al. (2017) teve uma relevante contribuição, ao propor um índice para identificar os municípios que seriam mais demandantes do programa e evidenciar que as regióes Norte e Nordeste, onde se concentraria essa maior demanda, não estavam tendo a prioridade que deveriam na alocação dos recursos. Nesse sentido, observa-se que as recomendaçôes de priorizar essas regióes vêm sendo consideradas pelos gestores do programa nos anos mais recentes. Os resultados aqui obtidos mostraram que as regiôes Norte e Nordeste foram menos afetadas pelas reduçóes de compras ocorridas nos últimos anos, apresentando um aumento proporcional de participação nas compras do PAA em relação às demais regiôes. Portanto, apesar dos cortes de recursos, o programa procurou compensar a redução de cobertura, melhorando a sua focalização nas regiôes mais prioritárias.

\subsection{Execução das compras do PAA nos municípios}

O valor total recebido pelos municípios no período variou de $\mathrm{R}$ \$314,12 a R \$ 51,9 milhôes, sendo o maior valor recebido por Santana do Mundaú (AL) (apêndice A). Para alguns municípios, os valores recebidos via PAA foram bem expressivos, considerando-se o tamanho da sua economia. No caso de Santana do Mundaú, por exemplo, município com cerca de 11 mil habitantes, em 2015, ano em que foi recebido o maior valor ( $\mathrm{R} \$ 11,8$ milhóes), este correspondeu a cerca 3,1\% do PIB municipal. Assim como este município, outros que receberam valores percentuais elevados de PAA em relação ao PIB localizam-se quase todos na regiáo Nordeste, sendo, em geral, municípios de pequeno ou médio porte, com índice de desenvolvimento municipal (IDFM) baixo ou regular. Estes resultados indicam que o PAA pode ter tido um papel relevante para a economia destes municípios no período analisado, visto que diversos estudos apontam que o programa tem efeitos positivos para a geração de receita para as famílias e a dinamização da economia local (Dias e Rocha, 2015; Santos, Soares e Benavides, 2015; Sambuichi et al., 2019a).

Aproximadamente $42 \%$ dos municípios que acessaram o PAA receberam entre $\mathrm{R} \$ 500$ mil a $\mathrm{R} \$ 5$ milhóes (gráfico 3), sendo que 225 municípios (5,7\%) receberam menos de $\mathrm{R} \$ 10$ mil no período. O valor médio recebido por município no Brasil e regióes apresentou tendência de queda no período, sendo que, no Brasil, este valor caiu de R\$ 334 mil, em 2012, para R\$ 109 mil em 2018 (gráfico 4). 
GRÁFICO 3

Percentual de municípios por classe de valor total recebido (2011-2018) ${ }^{1}$ (Em \%)

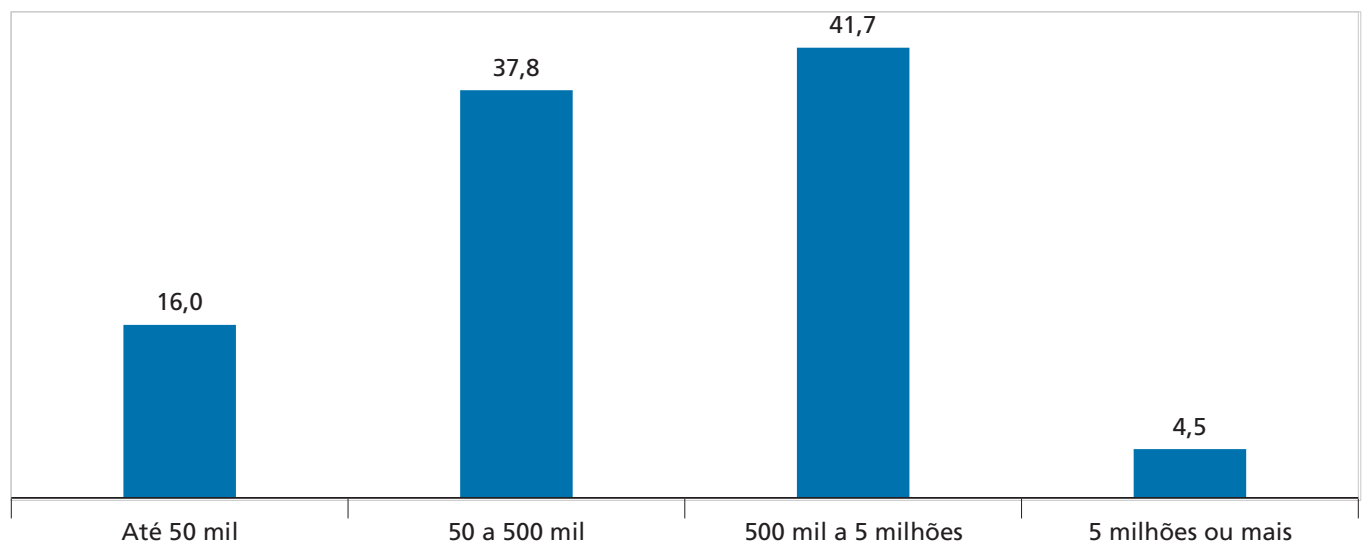

Fonte: Dados da pesquisa

Elaboração dos autores.

Nota: ' Valores em reais, corrigidos para dezembro de 2018 pelo IPCA-E.

GRÁFICO 4

Valor médio recebido por município, por ano, no Brasil e regiões (2011-2018) ${ }^{1}$

(Em R\$ mil)

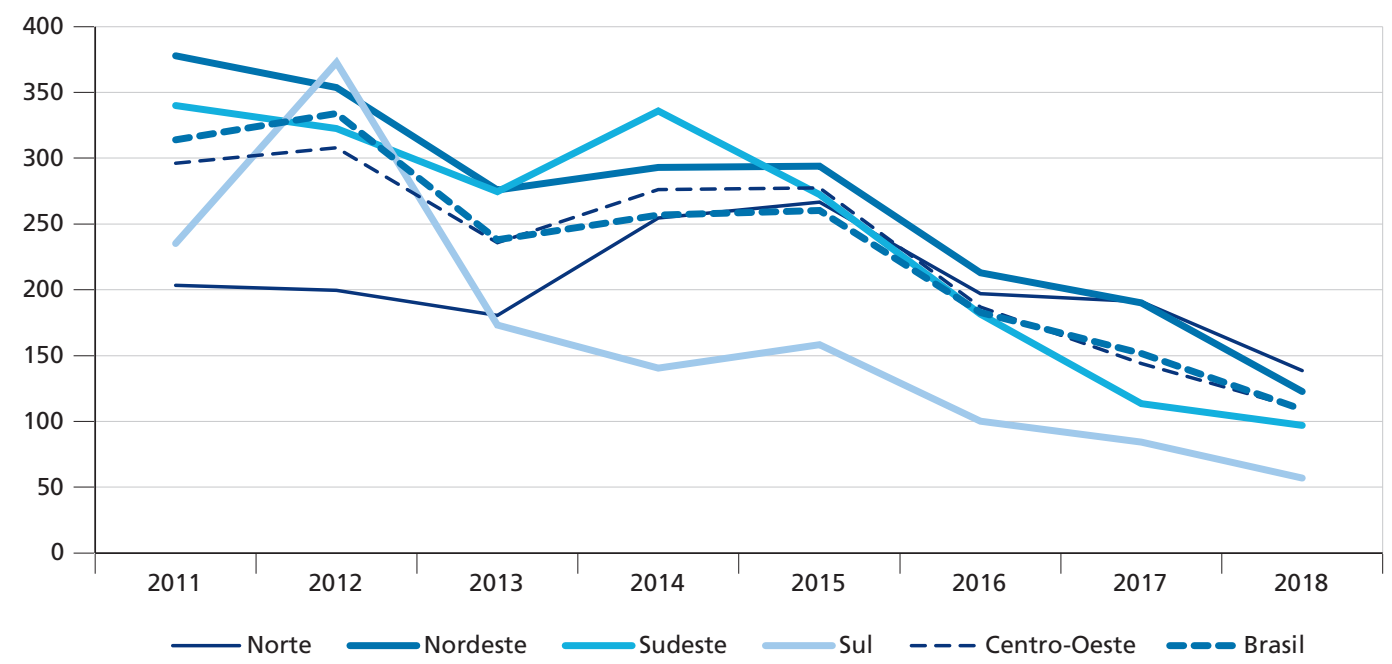

Fonte: Dados da pesquisa.

Elaboração dos autores.

Nota: ' Valores corrigidos para dezembro de 2018 pelo IPCA-E.

Cerca de metade dos municípios que acessaram o programa atenderam de 1 a 49 agricultores no período (gráfico 5), sendo que o número de agricultores por município variou de 1 a 2.442. O município de Santana do Mundaú (AL) teve o maior número 
de agricultores atendidos, seguido de Brasília (DF), com 1.984 agricultores. Destaca-se também que 267 municípios só tiveram um agricultor atendido no período (apêndice, tabela A.2), e cerca de 4 mil agricultores acessaram o programa em mais de um município. Mais da metade dos agricultores (54\%) acessaram o programa em apenas um ano ao longo do período, e apenas $0,08 \%$ acessou nos oito anos seguidos.

\section{GRÁFICO 5}

Percentual de municípios por classe de número de agricultores atendidos (2011-2018) (Em \%)

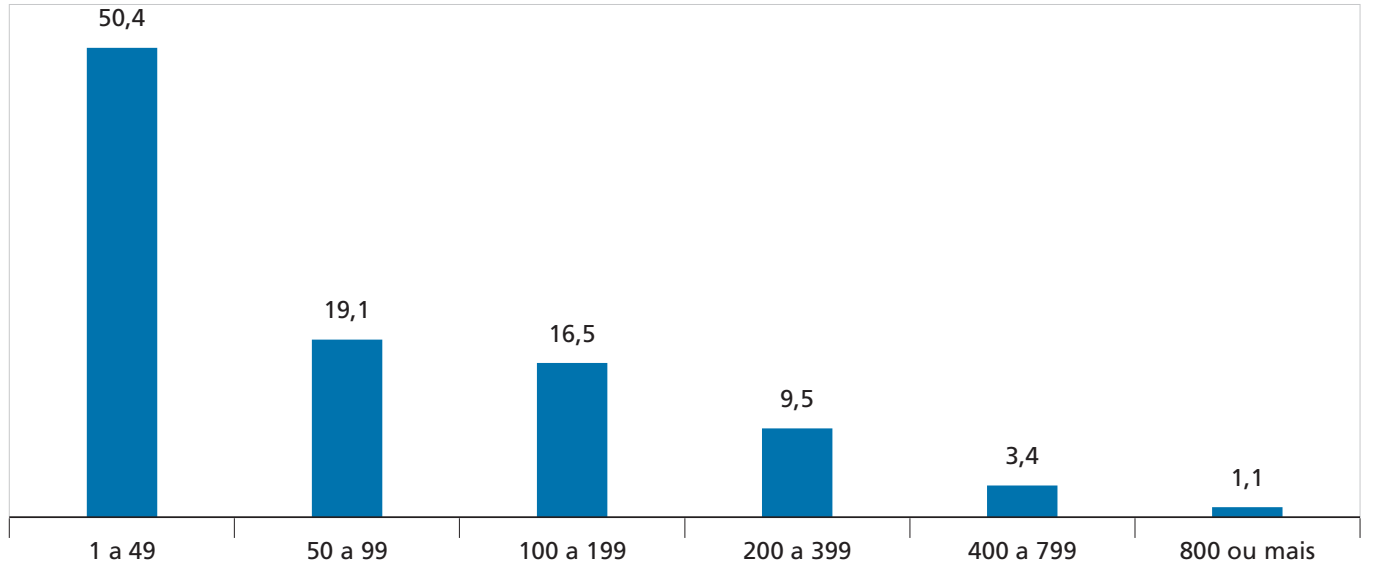

Fonte: Dados da pesquisa. Elaboração dos autores.

O número total de propostas de compras executadas, os valores médios aplicados, o número de agricultores e o número de municípios abrangidos por proposta variou muito entre operadores e modalidades ${ }^{6}$ (tabela 5). Entre os operadores, o maior número de propostas foi operado pela Conab, na modalidade CDS. As maiores propostas em valor de compras e número de agricultores e municípios foram executadas pelos estados, com valor médio de $\mathrm{R} \$ 7,4$ milhóes por proposta, abrangendo, em média, 1.342 agricultores, em 53 municípios. Nas operaçôes da Conab, as maiores propostas ocorreram na modalidade CDAF, com valor médio de $\mathrm{R} \$ 1,2$ milhão de reais. Observou-se, porém, uma grande variaçăo entre as propostas aprovadas de uma mesma modalidade ou operador, o que pode ser evidenciado pelos elevados desvios-padróes encontrados.

6. Esta análise não foi feita para as compras realizadas nas modalidades Leite, Compra Institucional e CDS operada por convênios, por não dispormos de microdados com identificação do número da proposta para estes casos específicos. 
TABELA 5

Número total de propostas de compras executadas, valores médios ${ }^{1}$ aplicados por proposta e número médio de agricultores e municípios abrangidos por proposta de compra no PAA operado pela Conab (nas diferentes modalidades) e pelos estados e municípios, via Termo de Adesão (2011-2018)

\begin{tabular}{|c|c|c|c|c|}
\hline & № total de propostas & $\begin{array}{l}\text { Valor médio por proposta }{ }^{2} \\
\text { (R\$ mil) }\end{array}$ & № médio de agricultores & № médio de municípios \\
\hline \multicolumn{5}{|l|}{ Conab } \\
\hline CDAF & 185 & $\begin{array}{r}1.227,6 \\
(2.833,6)\end{array}$ & $\begin{array}{r}131 \\
(264)\end{array}$ & $\begin{array}{r}11 \\
(14)\end{array}$ \\
\hline CDS & 9.424 & $\begin{array}{r}250,0 \\
(234,8)\end{array}$ & $\begin{array}{r}37 \\
(35)\end{array}$ & $\begin{array}{r}2 \\
(3)\end{array}$ \\
\hline Estoque & 731 & $\begin{array}{r}454,3 \\
(532,3)\end{array}$ & $\begin{array}{r}61 \\
(66)\end{array}$ & $\begin{array}{r}4 \\
(4)\end{array}$ \\
\hline Sementes & 54 & $\begin{array}{r}525,4 \\
(624,5)\end{array}$ & $\begin{array}{r}35 \\
(36)\end{array}$ & $\begin{array}{r}5 \\
(5)\end{array}$ \\
\hline Total & 10.394 & $\begin{array}{r}283,2 \\
(483,8)\end{array}$ & $\begin{array}{r}40 \\
(53)\end{array}$ & $\begin{array}{r}2 \\
(4)\end{array}$ \\
\hline \multicolumn{5}{|l|}{ Termo de Adesão ${ }^{4}$} \\
\hline Estados e Distrito Federal & 50 & $\begin{array}{r}7.436,9 \\
(8.625,3)\end{array}$ & $\begin{array}{r}1.342 \\
(1.207)\end{array}$ & $\begin{array}{r}53 \\
(42)\end{array}$ \\
\hline Municípios & 1.356 & $\begin{array}{r}330,4 \\
(452,9)\end{array}$ & $\begin{array}{r}64 \\
(74)\end{array}$ & $\begin{array}{r}3 \\
(4)\end{array}$ \\
\hline Total & 1.406 & $\begin{array}{r}583,1 \\
(2.139,1)\end{array}$ & $\begin{array}{r}109 \\
(336)\end{array}$ & $\begin{array}{r}5 \\
(13)\end{array}$ \\
\hline
\end{tabular}

Fonte: Dados da pesquisa.

Elaboração dos autores.

Notas: ' Desvio-padrão entre parênteses.

${ }^{2}$ Valores corrigidos para dezembro de 2018 pelo IPCA-E.

${ }^{3}$ Municííios que apresentaram pelo menos um agricultor que forneceu produtos para o programa.

${ }^{4}$ Para as operações via Termo de Adesão, os valores apresentados correspondem ao período 2012-2018, pois, antes de 2012, as compras da modalidade CDS

executadas pelos estados e municípios eram realizadas apenas por convênios realizados com o Ministério do Desenvolvimento Social, atual Ministério da Cidadania.

No caso do acesso ao PAA pela Conab, os resultados indicaram que as propostas executadas tendem a ser menores, especialmente na modalidade CDS, a mais executada por essa operadora. Essas propostas são elaboradas pelas organizaçóes de agricultores e abrangem poucos municípios, geralmente o município da organização e, ocasionalmente, algum município vizinho onde agricultores associados à organização possam estar estabelecidos. Devido ao acesso se dar por meio das organizaçóes, neste tipo de execução, portanto, a probabilidade de acesso deve ser maior nos territórios onde a agricultura familiar já se encontra mais bem organizada, o que corrobora os resultados do estudo realizado por Barth-Teixeira et al. (2017) sobre a atuação do PAA operado pela Conab. É preciso ressaltar, porém, que este mecanismo também pode estimular a organização dos agricultores, portanto, a recíproca também deve ser verdadeira. 
No caso da operação realizada pelos estados e municípios via Termo de Adesão, como os resultados mostraram, a execuçáo via estados permite o acesso mais pulverizado dos recursos e doaçóes de produtos entre os municípios, enquanto a execução municipal concentra mais os recursos nos municípios que elaboram as propostas, exigindo uma capacidade maior de articulaçâo do governo local. Em ambos os casos, porém, a possibilidade de acesso deve ser muito influenciada pela capacidade institucional dos governos estaduais e locais de se articularem para elaborar e viabilizar a execução das propostas (Chmiekewska, Souza e Lourete, 2010; Martins, 2013; Almeida, 2014). Entretanto, é preciso considerar ainda que existe a possibilidade de acesso pela proximidade, pois municípios vizinhos ao que executa a proposta podem também se beneficiar do programa, ao terem alguns agricultores locais incluídos entre os fornecedores da proposta executada pelo outro. Esta parece ser uma forma de acesso bem frequente, conforme se pode observar no presente estudo, devido ao elevado percentual de municípios que apresentaram poucos agricultores fornecedores.

\subsection{Caracterização dos municípios que forneceram para o programa}

Em relaçáo ao tamanho da população dos municípios que forneceram para o programa, observou-se um percentual de acesso acima de 70\% para todas as classes de tamanho, mostrando que o programa foi bem acessado por municípios de todos os tamanhos populacionais. Os municípios de tamanho médio, porém, foram os que acessaram mais, sendo que os municípios de 20.001 a 50.000 habitantes foram os que apresentaram maior percentual de acesso $(85,6 \%)$ e mais receberam recursos do PAA no período analisado (R\$1.416,7 milhôes). O valor médio recebido por município foi maior nas classes de tamanho mais elevadas (tabela 6). 
TABELA 6

Acesso dos municípios brasileiros ao PAA e valores totais aplicados, por classe de tamanho de população (2011-2018)

\begin{tabular}{|c|c|c|c|c|c|}
\hline \multirow{2}{*}{$\begin{array}{l}\text { Classe de tamanho da população } \\
\text { dos municípios }{ }^{1} \text { (no de habitantes) }\end{array}$} & \multirow{2}{*}{$\begin{array}{c}\text { № total de municípios } \\
\text { na classe }\end{array}$} & \multirow{2}{*}{$\begin{array}{l}\text { № de municípios que } \\
\text { acessaram o } \text { PAA }^{2}\end{array}$} & \multirow[t]{2}{*}{ Acesso (\%) } & \multirow{2}{*}{$\begin{array}{c}\text { Valor total aplicado }{ }^{3} \\
\text { (R\$ milhões) }\end{array}$} & \multirow{2}{*}{$\begin{array}{c}\begin{array}{c}\text { Valor médio por } \\
\text { município }\end{array} \\
\text { (R\$1 mil) }\end{array}$} \\
\hline & & & & & \\
\hline Até 5.000 & 1.255 & 932 & 74,3 & 445,2 & 477,7 \\
\hline De 5.001 a 10.000 & 1.214 & 935 & 77,0 & 731,3 & 782,1 \\
\hline De 10.001 a 20.000 & 1.380 & 1.141 & 82,7 & $1.355,2$ & $1.187,7$ \\
\hline De 20.001 a 50.000 & 1.071 & 917 & 85,6 & $1.416,7$ & $1.545,0$ \\
\hline De 50.001 a 100.000 & 351 & 292 & 83,2 & 607,8 & $2.081,7$ \\
\hline De 100.001 a 500.000 & 259 & 203 & 78,4 & 545,1 & $2.685,1$ \\
\hline Acima de 500.000 & 40 & 31 & 77,5 & 94,2 & $3.039,6$ \\
\hline Total & 5.570 & 4451 & 79,9 & $5.195,6$ & $1.167,3$ \\
\hline
\end{tabular}

As classes intermediárias de tamanho da população dos municípios - de 10.001 a 20.000 habitantes e de 20.001 a 50.000 habitantes - destacaram-se na obtençáo de recursos ao longo de todo o período analisado, com mais expressão nos anos de $2011 \mathrm{e}$ 2012. No período mais recente, outra classe que passou a se destacar foi a de 100.001 a 500.000 habitantes, apresentando uma tendência de crescimento proporcional em relação às demais classes (gráfico 6).

O PAA foi acessado principalmente pelos municípios com menor percentual de área urbana. Cerca de $82,6 \%$ dos municípios com menos de $1 \%$ de área urbana acessaram o programa no período (tabela 7). As duas classes com menos de $10 \%$ de área urbana receberam, juntas, 91,7\% dos recursos aplicados. Observa-se ainda que o programa foi acessado também pelos municípios totalmente urbanos, tendo sido o percentual de acesso, dentro da classe, de $46,4 \%$. Contudo, o percentual de recursos totais aplicados nesta classe de municípios foi muito baixo $(0,1 \%)$, considerando-se que os municípios nesta condição correspondem a aproximadamente $1,2 \%$ dos municípios brasileiros ( $0,7 \%$ dos municípios que acessaram o programa). 
GRÁFICO 6

Evolução dos valores totais aplicados, por classe de tamanho da população dos municípios (2011-2018)

(Em R\$ milhões)

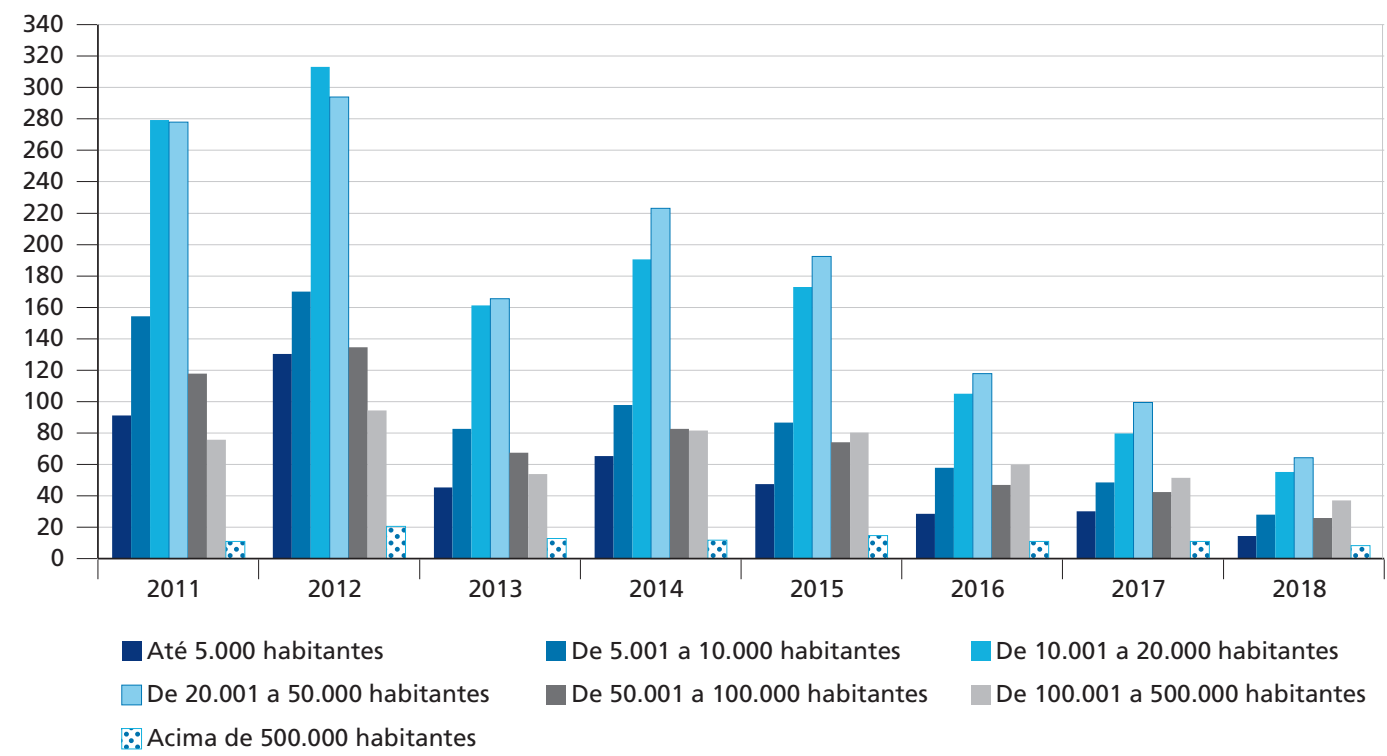

Fonte: Dados da pesquisa.

Elaboração dos autores.

Nota: 'Valores corrigidos para dezembro de 2018 pelo IPCA-E.

TABELA 7

Acesso dos municípios brasileiros ao PAA e valores totais aplicados, por classe de percentual de área urbana do município (2011-2018)

\begin{tabular}{lccccc}
\hline \multirow{2}{*}{ Classe (\%) } & $\begin{array}{c}\text { No total de municípios } \\
\text { na classe }\end{array}$ & $\begin{array}{c}\text { No de municípios que } \\
\text { acessaram o PAA }\end{array}$ & Acesso (\%) & \multicolumn{2}{c}{ Valor total aplicado $^{2}$} \\
\cline { 5 - 6 }$<1,0$ & 2.703 & 2.233 & 82,6 & $2.537,2$ & 48,8 \\
1,0 a 9,9 & 2.353 & 1.871 & 79,5 & $2.231,3$ & 42,9 \\
10,0 a 49,9 & 358 & 263 & 73,5 & 379,1 & 7,3 \\
50,0 a 99,9 & 80 & 48 & 60,0 & 41,4 & 0,8 \\
100 & 69 & 32 & 46,4 & 4,6 & 0,1 \\
Sem classificação & 7 & 4 & 57,1 & 2,0 & 0,0 \\
Total & 5.570 & 4.451 & 79,9 & $5.195,6$ & 100,0 \\
\hline
\end{tabular}

Fonte: Dados da pesquisa.

Elaboração dos autores.

Notas: ' Municípios que apresentaram pelo menos um agricultor que forneceu produtos para o programa; o número é apresentado para o total do período, sem repetição. ${ }^{2}$ Valores corrigidos para dezembro de 2018 pelo IPCA-E. 
Os maiores percentuais de acesso ocorreram na classe de baixo índice de desenvolvimento municipal (IDFM emprego e renda menor que 0,40), indicando que, no geral, municípios com baixo desempenho econômico tiveram, proporcionalmente, mais acesso ao programa. Observa-se, entretanto, que os percentuais de acesso foram elevados para todas as classes de desenvolvimento dos municípios. Em relação aos recursos, a maior proporção foi aplicada nas classes intermediárias de desempenho econômico, sendo que estas classes receberam, juntas, cerca de $80 \%$ do valor aplicado em compras (tabela 8).

TABELA 8

Acesso dos municípios brasileiros ao PAA e valores totais aplicados, por classe de índice de desenvolvimento do município (IFDM) emprego e renda (2011-2018)

\begin{tabular}{|c|c|c|c|c|c|}
\hline \multirow{2}{*}{ Classe de IDFM } & \multirow{2}{*}{$\begin{array}{c}\text { № total de municípios } \\
\text { na classe }\end{array}$} & \multirow{2}{*}{$\begin{array}{l}\text { № de municípios que } \\
\text { acessaram o PAA }\end{array}$} & \multirow{2}{*}{ Acesso (\%) } & \multicolumn{2}{|c|}{ Valor total aplicado } \\
\hline & & & & $\mathrm{R} \$$ milhões & $\%$ \\
\hline Baixo & 931 & 805 & 86,5 & 969,3 & 18,7 \\
\hline Regular & 3.404 & 2.731 & 80,2 & $2.978,0$ & 57,3 \\
\hline Moderado & 1.188 & 881 & 74,2 & $1.181,4$ & 22,7 \\
\hline Alto & 42 & 32 & 76,2 & 66,8 & 1,3 \\
\hline Sem classificação & 5 & 2 & 40,0 & 0,1 & 0,0 \\
\hline Total & 5.570 & 4.451 & 79,9 & $5.195,6$ & 100,0 \\
\hline
\end{tabular}

O percentual de acesso e o valor médio aplicado em compras do programa foi mais elevado nas classes de municípios com maior número de estabelecimentos que possuem DAP. O valor total aplicado, porém, foi maior nas classes intermediárias (com quantidade entre 50 e 499 estabelecimentos com DAP), as quais são as classes com maior número total de municípios (tabela 9).

TABELA 9

Acesso dos municípios brasileiros ao PAA e valores aplicados, por classe de número de estabelecimentos com DAP (2011-2018)

\begin{tabular}{|c|c|c|c|c|c|}
\hline $\begin{array}{l}\text { Classe de número de } \\
\text { estabelecimentos com }\end{array}$ & № total de municípios & № de municípios ${ }^{2}$ que & Acesso (\%) & Valor total aplicado ${ }^{3}$ & $\begin{array}{l}\text { Valor médio por } \\
\text { município }^{3}\end{array}$ \\
\hline & & & & (R\$ milhões) & (R\$ mil) \\
\hline$\leq 9$ & 460 & 234 & 50,9 & 69,8 & 298,3 \\
\hline 10 a 49 & 971 & 624 & 64,3 & 246,1 & 394,4 \\
\hline 50 а 249 & 2.163 & 1.758 & 81,3 & $1.492,4$ & 848,9 \\
\hline
\end{tabular}


(Continuação)

\begin{tabular}{|c|c|c|c|c|c|}
\hline \multirow{2}{*}{$\begin{array}{c}\text { Classe de número de } \\
\text { estabelecimentos com } \\
\text { DAP }^{1}\end{array}$} & \multirow{2}{*}{$\begin{array}{c}\text { № total de municípios } \\
\text { na classe }\end{array}$} & \multirow{2}{*}{$\begin{array}{l}\text { № de municípios }{ }^{2} \text { que } \\
\text { acessaram o PAA }\end{array}$} & \multirow[t]{2}{*}{ Acesso (\%) } & \multirow{2}{*}{$\frac{\text { Valor total aplicado }^{3}}{\text { (R\$ milhões) }}$} & \multirow{2}{*}{$\begin{array}{c}\begin{array}{c}\text { Valor médio por } \\
\text { município }^{3}\end{array} \\
\text { (R\$ mil) }\end{array}$} \\
\hline & & & & & \\
\hline 250 a 499 & 1.023 & 931 & 91,0 & $1.244,2$ & $1.336,5$ \\
\hline 500 a 999 & 610 & 575 & 94,3 & $1.191,3$ & $2.071,8$ \\
\hline$\geq 1.000$ & 343 & 329 & 95,9 & 951,8 & $2.893,1$ \\
\hline Total & 5.570 & 4451 & 79,9 & $5.195,6$ & $1.167,3$ \\
\hline
\end{tabular}

Fonte: Dados da pesquisa

Elaboração dos autores.

Notas: ' $C$ lassificação baseada nos dados do Censo Agropecuário de 2017.

${ }^{2}$ Municípios que apresentaram pelo menos um agricultor que forneceu produtos para o programa.

${ }^{3}$ Valores corrigidos para dezembro de 2018 pelo IPCA-E.

\subsection{Acesso às doações de alimentos da modalidade Compra com Doação Simultânea (CDS)}

Observou-se que, no período estudado, um total de 3.553 municípios receberam doaçóes do PAA CDS, enquanto 4.150 forneceram alimentos nesta modalidade, sendo que 802 municípios só forneceram e 205 só receberam doaçôes (tabela 10). Ressalta-se ainda que, quando consideramos todas as modalidades do PAA, foram observados 159 municípios que receberam doações do PAA CDS e não forneceram em nenhuma modalidade. Ao adicionarmos estes aos 4.451 municípios que forneceram produtos para o programa, constatamos que o número total de municípios beneficiados pelo PAA, em todas as modalidades, sobe para 4.610 , o que corresponde a cerca de $83 \%$ dos municípios brasileiros.

TABELA 10

Número de municípios que forneceram produtos e/ou receberam doações do PAA, modalidade CDS e PAA total (todas as modalidades) - Brasil e regiões (2011-2018)

\begin{tabular}{lcccccc}
\hline Região & $\begin{array}{c}\text { Forneceu produtos }- \\
\text { CDS }\end{array}$ & $\begin{array}{c}\text { Só forneceu }- \\
\text { CDS }\end{array}$ & $\begin{array}{c}\text { Recebeu doações }- \\
\text { CDS }\end{array}$ & Só recebeu - CDS & $\begin{array}{c}\text { Forneceu e/ou } \\
\text { recebeu CDS }\end{array}$ & $\begin{array}{c}\text { Forneceu e/ou } \\
\text { recebeu }- \\
\text { total PAA }\end{array}$ \\
\hline Norte & 403 & 18 & 390 & 5 & 408 & 412 \\
Nordeste & 1.463 & 176 & 1.352 & 65 & 1.528 & 1.642 \\
Sudeste & 1.018 & 326 & 764 & 72 & 1.090 & 1.123 \\
Sul & 967 & 226 & 779 & 38 & 1.005 & 1.106 \\
Centro-Oeste & 299 & 56 & 268 & 25 & 324 & 327 \\
Brasil & 4.150 & 802 & 3.553 & 205 & 4.355 & 4.610 \\
\hline
\end{tabular}

Fonte: Dados da pesquisa.

Elaboração dos autores. 
Quanto aos municípios que só forneceram, sem receber doações, observa-se que estes estiveram situados principalmente nas regióes Sudeste e Sul (tabela 10), e foram, em média, municípios de menor tamanho populacional, percentual de área urbana um pouco maior, menor número total de DAPs e com menos agricultores beneficiados pelo programa que os demais fornecedores da modalidade CDS (tabela 11). Cerca de $84 \%$ desses municípios apresentaram menos de 50 agricultores beneficiados, e mais da metade (54\%) apresentou menos de dez agricultores, enquanto nos demais municípios esses percentuais foram de $43 \%$ e $12 \%$.

Por sua vez, os municípios que só receberam doaçôes, sem fornecer produtos, situam-se principalmente na regiáo Sudeste (tabela 10), e foram, em média, municípios de maior população, mais fortemente urbanos e com menos estabelecimentos agropecuários aptos a acessar o programa (tabela 11).

TABELA 11

Média do tamanho populacional, percentual de área urbana, número de estabelecimentos com DAP e número de agricultores fornecedores, para os municípios que só forneceram produtos e os que só receberam doações, em relação aos demais municípios que acessaram (2011-2018)

\begin{tabular}{|c|c|c|c|c|c|c|}
\hline & Só forneceu produtos & Demais municípios & & Só recebeu doações & Demais municípios & \\
\hline População (1 mil habitantes) & $\begin{array}{r}19,0 \\
(38,5)\end{array}$ & $\begin{array}{r}46,1 \\
(265,0)\end{array}$ & $* * *$ & $\begin{array}{r}80,3 \\
(192,6)\end{array}$ & $\begin{array}{r}39,2 \\
(242,1)\end{array}$ & * \\
\hline Percentual de área urbana (\%) & $\begin{array}{r}5,1 \\
(13,5)\end{array}$ & $\begin{array}{r}4,8 \\
(14,1)\end{array}$ & * & $\begin{array}{r}16,7 \\
(30,5)\end{array}$ & $\begin{array}{r}4,2 \\
(12,3)\end{array}$ & $* * *$ \\
\hline № de estabelecimentos com DAP & $\begin{array}{r}212,8 \\
(283,3)\end{array}$ & $\begin{array}{r}367,8 \\
(498,0)\end{array}$ & $* * *$ & $\begin{array}{r}173,8 \\
(324,7)\end{array}$ & $\begin{array}{r}347,4 \\
(474,3)\end{array}$ & $* * *$ \\
\hline № de agricultores fornecedores & $\begin{array}{r}13,5 \\
(31,0)\end{array}$ & $\begin{array}{r}98,4 \\
(147,8)\end{array}$ & $* * *$ & - & - & \\
\hline
\end{tabular}

Fonte: Dados da pesquisa.

Elaboração dos autores.

Obs.: ' Significância da diferença entre as médias, teste t: ${ }^{*} p<0,05 ;{ }^{* *} p<0,01 ;{ }^{* * *} p<0,001$ ${ }^{2}$ Desvio-padrão entre parênteses.

Esses resultados indicam haver interações entre municípios vizinhos no processo de fornecimento e recebimento das doaçôes, constituindo-se este também em um ponto importante a ser investigado em análises futuras. No caso dos municípios que apenas forneceram, sem receber doaçôes na modalidade CDS, por exemplo, estes podem ser municípios pequenos que não apresentam entidades beneficiárias suficientes para demandar os produtos, e podem estar entregando em municípios próximos que têm maior demanda. Por seu turno, quanto àqueles municípios que só receberam doaçóes, sem fornecer produtos, pode dar-se o caso de não possuírem capacidade produtiva para suprir a demanda por alimentos in natura, dado que estes municípios apresentam como características uma população maior (em média), maiores áreas urbanas e um menor número de estabelecimentos aptos para fornecer ao PAA. 


\subsection{Análise binomial logística do acesso dos municípios ao programa - município do agricultor}

Em relação à análise de regressão binomial logística, quase todas as variáveis explicativas testadas no modelo apresentaram coeficientes significantes, com exceção da dummy para a região Sudeste. Os resultados encontrados apresentaram as mesmas tendências observadas nas análises descritivas, mostrando que essas tendências se confirmam mesmo quando se controla pelo efeito das demais variáveis. As variáveis IFDM emprego e renda e percentual de área urbana apresentaram coeficientes negativos, indicando que municípios com melhor desempenho econômico e maior grau de urbanização apresentam menor probabilidade de acesso ao programa. A probabilidade de acesso se mostrou maior para municípios com maior número de agricultores aptos a acessar o programa e pertencentes a regióes metropolitanas. A relação do acesso com o tamanho da população do município foi positiva, porém, não linear, apresentando-se significante para o logaritmo do tamanho populacional, o que se explica pelo fato de o acesso ter sido maior nas classes intermediárias de tamanho. Em relação às regiōes, os municípios pertencentes às regióes Norte, Nordeste e Sul apresentaram maior probabilidade de acesso que os municípios da regiáo omitida, no caso, a região Centro-Oeste (tabela 12).

TABELA 12

Parâmetros estimados no modelo de regressão logística - variável dependente: acesso ao PAA (2011-2018)

\begin{tabular}{|c|c|c|c|c|c|}
\hline Variável & Coeficiente & Desvio-padrão & Valor de Z & $\operatorname{Pr}(>|z|)$ & \\
\hline Intercept & $-2,497$ & 0,384 & $-6,503$ & $7,8 e^{-11}$ & $* * *$ \\
\hline IFDM emprego e renda & $-1,719$ & 0,466 & $-3,692$ & $2,2 e^{-4}$ & $* * *$ \\
\hline Logaritmo do tamanho populacional & 0,894 & 0,108 & 8,248 & $<2,0 \mathrm{e}^{-16}$ & $* * *$ \\
\hline Percentual de área urbana & $-0,028$ & 0,003 & $-8,590$ & $<2,0 \mathrm{e}^{-16}$ & $* * *$ \\
\hline Número de estabelecimentos com DAP & 0,002 & $2,4 e^{-4}$ & 9,617 & $<2,0 \mathrm{e}^{-16}$ & $* * *$ \\
\hline Região metropolitana (dummy) & 0,312 & 0,112 & 2,785 & $5,4 e^{-3}$ & ** \\
\hline Região Norte (dummy) & 1,440 & 0,201 & 7,161 & $8,0 e^{-13}$ & $* * *$ \\
\hline Região Nordeste (dummy) & 0,960 & 0,145 & 6,605 & $4,0 e^{-11}$ & $* * *$ \\
\hline Região Sudeste (dummy) & $-0,143$ & 0,121 & $-1,177$ & 0,239 & \\
\hline Região Sul (dummy) & 1,723 & 0,154 & 11,174 & $<2,0 \mathrm{e}^{-16}$ & $* * *$ \\
\hline \multirow{2}{*}{ Resíduos } & Mínimo & $1 \mathrm{Q}$ & Mediana & $3 Q$ & Máximo \\
\hline & $-4,461$ & 0,106 & 0,430 & 0,637 & 2,324 \\
\hline Número de observações & 4971 & & & & \\
\hline PseudoR__(McFadden) & 0,200 & & & & \\
\hline
\end{tabular}

Fonte: Dados da pesquisa.

Elaboração dos autores.

Obs.: ${ }^{*} \mathrm{p}<0,05 ;{ }^{* *} \mathrm{p}<0,01 ;{ }^{* * *} \mathrm{p}<0,001$. 
Considerando-se as finalidades e prioridades do programa, os resultados das análises descritivas e da análise binomial logística, no geral, estão de acordo com o que seria esperado, tendo o programa apresentado maior probabilidade de acesso por municípios menos urbanos, com mais agricultores familiares, com menor IFDM emprego e renda e pertencente às regióes Norte e Nordeste. Esses resultados corroboram as conclusóes dos estudos realizados por Simão, Silva e Silveira (2014) e Salgado et al. (2017), que mostraram a eficácia de focalização do programa em atingir os municípios que apresentariam maior demanda pelos seus benefícios.

A análise binomial logística mostrou também um aumento da probabilidade de acesso para os municípios que pertencem a regiōes metropolitanas. Esse fato já tinha sido observado no estudo realizado por Santos et al. (2015), o qual mostrou que o número de registros de agricultores vinculados ao PAA tinha uma forte correlaçáo positiva com as concentraçóes populacionais, em especial as regióes metropolitanas. Conforme explicam esses autores, tal fato pode estar relacionado aos cinturões verdes e também à maior demanda pelo consumo de produtos apresentada pelos municípios pertencentes a essas regiōes. Além disso, fatores como a maior facilidade de logística de transporte e melhor capacidade institucional e administrativa podem também estar influenciando a maior facilidade de acesso desses municípios.

É importante ressaltar, porém, que o valor do pseudo $R^{2}$ estimado foi baixo $(0,2)$, o que indica que as variáveis utilizadas no modelo, embora significantes, explicam pouco da variação observada nos dados. Isto quer dizer que há outras variáveis importantes que também podem estar influenciando na implementaçáo do PAA, e que não foram incluídas no modelo utilizado. Para estudos futuros, recomenda-se o aprofundamento dessas análises, principalmente com a inclusão de indicadores que permitam avaliar melhor a influência da capacidade institucional dos municípios e da proximidade geográfica sobre a probabilidade de acesso.

\section{PANORAMA E AS PERSPECTIVAS DO PAA NA ATUALIDADE}

Desde a sua criação, o PAA passou por um processo de aprendizado e aperfeiçoamento que levou o programa a estruturar e consolidar os seus procedimentos burocráticos, os quais deram estabilidade na implementação da política pública (Almeida, Perin e 
Sambuichi, 2019). Porém, os recursos destinados ao PAA não acompanharam o fortalecimento do programa, oriundo do seu aprimoramento, das relaçôes de reciprocidade e das redes formadas em torno dele. Os resultados mostraram que os recursos disponibilizados para o PAA foram drasticamente reduzidos nos últimos anos, sendo que o valor aplicado em 2018 foi cerca de um quinto do valor de 2012. Acredita-se que os valores aplicados em 2019 tenham sido ainda menores que os de 2018, embora os microdados deste último ano ainda não estivessem disponíveis para se fazer a estimativa quando foram realizadas as análises apresentadas neste texto.

Observou-se, também, uma pulverização dos recursos financeiros do programa. Isso quer dizer que, além da redução total de recursos, houve ainda uma expressiva diminuição dos valores recebidos por cada um dos municípios atendidos. A consequência disto é a redução da capacidade do PAA de produzir impactos na comercializaçáo, geração de renda e dinamização econômica local, o que pode trazer desestímulos à produção agropecuária de pequeno porte. Além disso, diminui a amplitude da política no que tange à promoção da segurança alimentar e nutricional no nível local.

As justificativas para a redução dos recursos destinados ao PAA foram uma mudança de agenda e de prioridades de políticas públicas e o agravamento da situação econômica do Brasil desde 2014, um período de alta instabilidade, que caracterizou uma das maiores contraçóes de renda da história do país, acompanhada de intensa queda do PIB, principalmente nos anos de 2015 e 2016 (IBGE, 2017). Apesar da leve recuperação nos anos de 2018 e 2019, o patamar econômico anterior a 2014 ainda não foi retomado (Souza Júnior et al., 2019).

Além da grave crise econômica, atualmente o Brasil enfrenta uma crise sanitária, provocada pela pandemia do novo coronavírus. O impacto econômico da Covid-19 poderá ser de alta gravidade, sobretudo porque abrange os mercados financeiros mundiais. De acordo com a Organização das Nações Unidas para Alimentação e Agricultura (FAO) (2020a), torna-se imprescindível, neste momento, juntar esforços para que se evitem paralisaçôes abruptas na produção doméstica e na geração de renda, a fim de se alcançar um menor impacto negativo no âmbito econômico e social.

Em vez de políticas recessivas e de ajustes fiscais como medidas de enfrentamento à crise, os organismos internacionais - como a FAO, a Organização Mundial da Saúde (OMS) e a Organização Mundial do Comércio (OMC) - expóem a relevância da 
expansão do gasto público com políticas públicas sociais, bem como com aquelas voltadas à compras governamentais usadas enquanto instrumento para escoar a produção e manter a cadeia de suprimentos ativa (FAO, 2020b).

A crise econômica, somada agora à Covid-19, poderá ter impactos negativos nos municípios brasileiros, agravando o quadro econômico que já estava fragilizado, principalmente porque muitos deles já operam com grandes dificuldades do ponto de vista fiscal e orçamentário. São exatamente estes municípios que apresentam as maiores necessidades e demandas por políticas públicas como PAA. Acredita-se que o modus operandi do programa, bem como todo o arcabouço de medidas que a política pública contempla, tem condiçôes de produzir efeitos positivos, tanto para o fortalecimento da agricultura familiar e dinamização da economia, quanto no âmbito da promoção da segurança alimentar e nutricional.

Do ponto de vista da agricultura familiar e da economia, o PAA apresenta características importantes de incentivo à produção descentralizada de alimentos no Brasil e aproxima o produtor do consumidor final. Isso poderá reduzir o risco de desabastecimento ou a necessidade de se recorrer a grandes centrais, que podem apresentar alta volatilidade de preços diante da crise. Além disso, os circuitos curtos de comercialização incentivados pelo programa têm como efeitos a dinamização e diversificação da atividade econômica em âmbito local e regional (Rambo e Denz, 2015). Esses elementos tendem a funcionar como amortecedores do risco de colapso econômico.

No âmbito da segurança alimentar e nutricional, o PAA também pode atuar para mitigar os efeitos das crises, operando em três frentes: $i$ ) no fortalecimento da rede de assistência social e da rede de equipamentos de segurança alimentar, tendo em vista que a modalidade CDS prevê a doação de alimentos a estas entidades; ii) na ampliação do acesso e melhoria da quantidade e qualidade de alimentos, pois incentiva a diversificação produtiva e apresenta instrumentos de controle para garantir a qualidade do produto doado; e iii) no auxílio ao combate de infecçóes e fortalecimento do sistema imunológico, por meio do aumento do consumo de alimentos in natura e minimamente processados, os quais são ricos em vitaminas e antioxidantes (Antunes e Hespanhol, 2011; Barth-Teixeira et al., 2017; FAO, 2020b). 
O PAA é hoje um programa que reúne um conjunto de benefícios na promoção da segurança alimentar e nutricional, na dinamização da economia local e no fortalecimento da agricultura familiar, evidenciados em pesquisas realizadas em diversas localidades do Brasil. A experiência do programa tornou-se referência para agricultores familiares de países da América Latina, Caribe e África (FAO, 2017), e ele é reconhecido pela FAO como uma política pública que contribuiu de maneira ativa para a reduçáo expressiva da fome, desnutrição, subalimentação e saída do Brasil do mapa da fome da ONU em 2014 (FAO, 2014).

Em face à pandemia provocada pelo novo coronavírus, o Brasil se comprometeu, por meio de declaração assinada também por organismos internacionais especializados e por demais países da América Latina e Caribe, a contribuir com a coordenação de políticas públicas de apoio à produção e comercialização e com a construção de medidas para garantir o abastecimento alimentar durante a crise epidemiológica (FAO, 2020c). Entre as medidas adotadas pelo governo federal para isso, está a Medida Provisória (MP) $n^{\circ}$ 957, de 24 de abril de 2020, a qual abriu crédito extraordinário em favor do Ministério da Cidadania no valor de $\mathrm{R} \$ 500$ milhôes, a ser utilizado na operação do PAA. A aplicação desse recurso será muito importante para o funcionamento do programa, pois o valor total que estava previsto no Orçamento Federal de 2020 para ser aplicado neste ano, incluindo as emendas parlamentares, era de apenas $R \$ 186$ milhões, e já vinha sofrendo contingenciamentos. Portanto, sem esse crédito extraordinário, o PAA iria operar, neste ano, com ainda menos recursos que em 2018, o que seria muito ruim, especialmente considerando-se as potencialidades do programa para enfrentar os efeitos da crise sanitária atual.

Apesar dos seus comprovados benefícios e do seu potencial para atuar favoravelmente em resposta aos desafios deste momento, o PAA apresenta atualmente um elemento desfavorável ao seu processo de implementação e fortalecimento enquanto política pública: o enfraquecimento das instâncias de participação e controle social via conselhos. Mudanças recentes na legislaçáo federal, realizadas principalmente a partir de 2019, extinguiram ou enfraqueceram conselhos importantes para a promoção da participação social e da segurança alimentar e nutricional, como é o caso do Consea. Essas mudanças enfraquecem também os Conseas em estados e municípios, que ficam sem centralização para a condução de açóes de caráter local. A ausência de instrumentos de participação e controle social atuantes interfere, também, na capacidade 
de mobilização de agricultores familiares e demais agentes que envolvem o PAA para demandar do poder público local o apoio logístico e a demonstração de interesse em acessar o programa, pois, conforme indicam diversos estudos empíricos, tais instrumentos sáo importantes para viabilizar o acesso ao programa (Silva e Schmitt, 2012; Froehlich e Schneider, 2013; Veloso 2017; Neto e Hespanhol, 2018).

\section{CONSIDERAÇÕES FINAIS}

Este trabalho analisou os quantitativos das operaçóes realizadas pelo PAA no período de 2011 a 2018, mostrando que o programa beneficiou mais de 450 mil de agricultores familiares, público este que inclui agricultores, pecuaristas, silvicultores, aquicultores, extrativistas, pescadores artesanais, povos indígenas e povos remanescentes de quilombos rurais e demais povos e comunidades tradicionais. O programa adquiriu quantidade superior a 2 milhóes de toneladas de alimentos, conseguindo atingir beneficiários fornecedores e/ou consumidores em cerca de $83 \%$ dos municípios brasileiros, números que mostram sua ampla capilaridade.

As análises realizadas mostraram que a probabilidade de acesso ao programa foi maior para municípios com menor desenvolvimento econômico, menos urbanos, com mais agricultores familiares e pertencentes às regiōes Norte e Nordeste. Esses dados indicam que o programa está tendo eficácia na sua focalização em atender prioritariamente as regiôes mais carentes de desenvolvimento rural, bem como aqueles municípios que mais demandam atendimento para o público que vive em vulnerabilidade alimentar e social. Observou-se também que houve aumento da probabilidade de acesso para os municípios localizados em regiốes metropolitanas. A explicaçáo para isso pode ser tanto pela alta demanda, originada no aumento de pessoas em situaçáo de risco social, quanto pela capacidade de escoar os produtos da agricultura familiar que estas regiōes possuem.

Os resultados corroboraram os estudos encontrados na literatura que apontam o PAA como um importante canal de comercializaçáo para a agricultura familiar, capaz de promover o aumento da renda, a inclusão produtiva e a dinamizaçáo da economia local, além de contribuir para a segurança alimentar e nutricional, por meio da distribuição de alimentos às pessoas em situação de insegurança alimentar e nutricional. Dessa forma, por todos os benefícios gerados pelo PAA e por sua capacidade de atuação 
horizontal e multidisciplinar, e considerando-se, ainda, as previsões nacionais e internacionais de possível piora no quadro epidemiológico e econômico diante do contexto atual, acredita-se que o programa seja uma ferramenta relevante a ser utilizada como instrumento mitigador de efeitos negativos, nos âmbitos econômico e social, durante e após a Covid-19.

Observou-se, porém, uma expressiva diminuição dos recursos aplicados no PAA nos últimos anos, além de uma pulverizaçáo dos recursos entre os municípios, o que pode reduzir a sua capacidade de gerar benefícios e atuar positivamente na mitigação dos impactos da crise. Outro ponto negativo é a extinção ou enfraquecimento dos conselhos de âmbito federal, que atuavam como instâncias de participação e controle social do programa. Por essa razão, reforça-se a necessidade de ampliar o investimento de recursos no PAA, neste e nos próximos anos, além recuperar o papel dos conselhos, de forma a se garantir que o programa possa atingir as suas finalidades e atuar adequadamente no combate aos atuais desafios.

\section{REFERÊNCIAS}

ALMEIDA, A. F. C. S.; PERIN, G.; SAMBUICHI, R. H. O Programa de Aquisição de Alimentos (PAA) analisado em três dimensôes: benefícios, amadurecimento e perspectivas para a política. In: CONGRESSO INTERNACIONAL DE DESEMPENHO DO SETOR PÚBLICO, 3., 2019, Florianópolis, Santa Catarina. Anais... Florianópolis: CIDESP, 2019.

ALMEIDA, T. S. Desafios institucionais e organizacionais para a execuçáo do Programa de Aquisiçáo de Alimentos (PAA) da Agricultura Familiar: o caso do município de Gravataí-RS. 2014. Monografia (Graduação) - Universidade Federal do Rio Grande do Sul, Porto Alegre, 2014. Disponível em: <https://bit.ly/2MUU2yv>.

ANTUNES, M. V. M.; HESPANHOL, R. A. M. O Programa de Aquisição de Alimentos no município Dracena-SP. Caderno Prudentino de Geografia, v. 33, n. 2, p. 101-122, 2011.

BALSADI, O. V. Programa de Aquisição de Alimentos da Agricultura Familiar: os primeiros resultados obtidos em 2003. Informaçóes Econômicas, v. 34, n. 5, p. 35-46, 2004.

BARTH-TEIXEIRA, E. et al. Análise da operacionalizaçáo do Programa de Aquisição de Alimentos (PAA/Conab) no Território Cantuquiriguaçu-PR. In: CONGRESSO DA SOCIEDADE BRASILEIRA DE ECONOMIA, ADMINISTRAÇÃO E SOCIOLOGIA RURAL, 55. 2017, Santa Maria, Rio Grande do Sul. Anais... Santa Maria: SOBER, 2017. Disponível em: $<$ https://bit.ly/2BjuuXl>. 
BRASIL. Lei no 10.696 , de 2 de julho de 2003. Dispóe sobre a repactuação e o alongamento de dívidas oriundas de operaçóes de crédito rural, e dá outras providências. Diário Oficial da União, Brasília, p. 1, 3 jul. 2003. Seção 1.

Secretaria de Avaliação e Gestão da Informação. Ministério do Desenvolvimento Social e Combate à Fome. Avaliaçáo do Programa de Aquisiçáo de Alimentos modalidade leite (PAA-leite) e das famílias dos beneficiários consumidores do leite. Brasília: MDSCF, 2011.

. Decreto no 7.775, de 4 de julho de 2012. Regulamenta o art. 19 da Lei no 10.696, de 2 de julho de 2003, que institui o Programa de Aquisição de Alimentos, e o Capítulo III da Lei no 12.512, de 14 de outubro de 2011, e dá outras providências. Diário Oficial da Uniáo, Brasília, p. 3, 5 jul. 2012. Seção 1.

Portaria no 350, de 15 de abril de 2020. Designa a composição do Grupo Gestor do Programa de Aquisição de Alimentos. Diário Oficial da Uniáo, Brasília, p. 1, 16 abr. 2020. Seção 1.

CAVAlCANTI, N. T. F; MARJOTTA-MAISTRO, M. C.; ARAÚJO, H. Análise do Programa de Aquisição de Alimentos (PAA) no estado de Pernambuco nos anos de 2011-2014. Cadernos de Agroecologia, v. 13, n. 1, 2018.

CHMIEKEWSKA, D.; SOUZA, D.; LOURETE, A. A. O Programa de Aquisiçáo de Alimentos da Agricultura Familiar (PAA) e as práticas dos agricultores participantes orientadas ao mercado: estudo de caso no Estado de Sergipe. Brasília: Ipea, 2010. (Texto Para Discussão, n. 1510).

DIAS, T. F.; ROCHA, L. A. O Programa de Aquisição de Alimentos da Agricultura Familiar (PAA) e seus efeitos nos municípios do Rio Grande do Norte - 2005 a 2011 . Administraçáo Pública e Gestão Social, v. 7, n. 1, p. 16-25, 2015.

FAO - FOOD AND ALGRICULTURE ORGANIZATION OF THE UNITED NATIONS. Relatório do estado da segurança alimentar e nutricional no Brasil. Brasília: FAO, 2014.

. Países sul-americanos buscam expertise brasileira em compras públicas. Brasília: FAO, 2017. Disponível em: <https://bit.ly/34phBZF>. Acesso em: 1 maio 2020.

Maintaining a healthy diet during the COVID-19 pandemic. Rome: FAO, 2020a.

Mitigating impacts of COVID-19 on food trade and markets. Rome: FAO, 2020b.

FAO no Brasil - 25 países de América Latina e do Caribe se coordenam para apoiar o funcionamento regular do sistema alimentar durante a crise da Covid-19. Brasília: FAO, 2020c. Disponível em: <https://bit.ly/30h5Ym2>. Acesso em: 3 abr. 2020.

FROEHLICH, E.; SCHNEIDER, S. Condicionantes legais e estratégias de governança para a aquisição de produtos da agricultura familiar para a alimentação escolar via o Programa de Aquisição de Alimentos: o caso de Tapes, no Rio Grande do Sul. In: DEL GROSSI, M. E.; 
KROEFF, D. R. (Orgs.). PAA: 10 anos de aquisição de alimentos. 1. ed. Brasília: MDS, 2013. p. 209-231.

GRAZIANO DA SILVA, J. Agricultura familiar e sustentabilidade. Eco21, 2019. Recuperado de: <https://bit.ly/30eivqv>. Acesso em: 20 jan. 2020.

GRISA, C. et al. O Programa de Aquisição de Alimentos (PAA) em perspectiva: apontamentos e questóes para o debate. Retratos de Assentamentos, n. 13, p. 137-170, 2010.

GRISA, C. et al. Contribuiçóes do Programa de Aquisição de Alimentos à segurança alimentar e nutricional e à criação de mercados para a agricultura familiar. Agriculturas, v. 8, n. 3, p. 34-41, 2011.

HESPANHOL, A. N. Agricultura, desenvolvimento e sustentabilidade. In: MARAFON, G. J.; RIBEIRO, M. A.; RUA, J. (Orgs.). Abordagens teórico-metodológicas em Geografia Agrária. Rio de Janeiro: EDUERJ, 2007. p. 179-198.

IBGE - INSTITUTO BRASILEIRO DE GEOGRAFIA ESTATÍSTICA. Censo Agropecuário 2006 - Agricultura familiar. Rio de Janeiro: IBGE, 2006.

. Sistema de contas nacionais: Brasil 2017. Contas Nacionais, v. 67, p. 1-12, 2017.

. Censo Agropecuário 2017. Rio de Janeiro: IBGE, 2019.

. Estimativas de População - EstimaPop. Rio de Janeiro: IBGE, 2020. Disponível em: $<$ https://bit.ly/3jljT2c>. Acesso em: 20 mar. 2020.

KAGEYAMA, A. A.; BERGAMASCO, S. M. P. P.; OLIVEIRA, J. T. A. Uma tipologia dos estabelecimentos agropecuários do Brasil a partir do Censo de 2006. Revista de Economia e Sociologia Rural, v. 51, n. 1, p. 105-122, 2013.

MACÍAS, J. D. Circuitos alimentarios de proximidad: um acercamiento al anclaje territorial de formas emergentes de producción y consumo rururbanas. In: PERAFÁN, M. E. V. et al. Gestão e Dinâmica em Desenvolvimento Territorial. Curitiba: Editora CRV, p. 119-136, 2018.

MARTINS, S. P. PAA Leite: contexto de implantação, desenvolvimento e possibilidades de aprimoramento. In: DEL GROSSI, M. E.; KROEFF, D. R. (Orgs.). PAA: 10 anos de aquisição de alimentos. 1. ed. Brasília: MDS, p. 75-111, 2013.

NETO, C. C. N.; HESPANHOL, R. A. M. A descentralização político-administrativa e a execução do Programa de Aquisição de Alimentos (PAA) no município de Irapuru (SP). Espaço em Revista, v. 20, n. 1, p. 1-21, 2018.

RAMBO, A. G.; DENZ, E. VON. Circuitos curtos de comercialização fomentando novos usos do território: consideraçóes sobre o PNAE e as feiras livres. In: SEMINÁRIO INTERNACIONAL SOBRE DESENVOLVIMENTO REGIONAL NO BRASIL, 7., 2015. Santa Cruz do Sul, Rio Grande do Sul. Anais... Santa Cruz do Sul: UNISC, 2015. 
SALGADO, R. J. S. F. et al. Focalização e Cobertura do Programa de Aquisição de Alimentos (PAA): avaliação de sua eficácia nas regiôes brasileiras. Revista de Economia e Sociologia Rural, v. 55, n. 4, p. 661-678, 2017.

SAMBUICHI, R. H. R. et al. Programa de Aquisiçáo de Alimentos e segurança alimentar: modelo lógico, resultados e desafios de uma política pública voltada ao fortalecimento da agricultura familiar. Brasília: Ipea, 2019a. (Texto para Discussão, n. 2482).

SAMBUICHI, R. H. et al. Diversidade de Produtos Adquiridos pelo Programa de Aquisição de Alimentos no Brasil e Regióes. Boletim Regional, Urbano e Ambiental, p. 109-116, 2019 b.

SANTOS, J. R. et al. Efeitos da densidade populacional e proximidade de aglomerados urbanos sobre o nível de efetividade do Programa de Aquisição de Alimentos (PAA) no Brasil. Scientia Plena, v. 11, n. 2, p. 1-11, 2015.

SANTOS, S. R. Q.; SOARES, N. S.; BENAVIDES, Z. A. C. Programa de Aquisição de Alimentos da agricultura familiar (PAA): o caso dos produtores de Ibicaraí-Ba. Revista de Estudos Sociais, v. 17, n. 33, p. 161-182, 2015.

SCHMITT, C. J. Aquisição de alimentos da agricultura familiar: integração entre política agrícola e segurança alimentar e nutricional. Revista de Política Agrícola, n. 2, p. 78-88, 2005.

SILVA, M. K.; SCHMITT, C. J. Políticas em rede: uma análise comparativa das interdependências entre o Programa de Aquisiçâo de Alimentos e as redes associativas no Rio Grande do Sul e na Bahia. In: ENCONTRO ANUAL DA ASSOCIAÇÃO NACIONAL DE PÓS GRADUAÇÃO E PESQUISA EM CIÊNCIAS SOCIAS (ANPOCS), 36., 2012. Águas de Lindóia, São Paulo. Anais... Águas de Lindóia: Anpocs, 2012.

SIMÃO, G. L.; SILVA, E. A.; SILVEIRA, S. D. F. R. Grau de Cobertura do Programa de Aquisição de Alimentos (PAA) Junto aos Agricultores Familiares do Estado de Minas Gerais. Revista de Economia e Sociologia Rural, v. 52, n. 3, p. 533-548, 2014.

SOUSA, C. S. Políticas Públicas para a Agricultura Familiar: um estudo sobre a descontinuidade do Programa Mais Gestão. Dissertação (Mestrado) - Universidade de Planaltina, 2018. Disponível em: <https://bit.ly/2S7gyaQ>.

SOUZA JÚNIOR, J. R. C. S. et al. Visão geral da conjuntura. Carta de Conjuntura do Ipea, Brasília, v. 45, p. 1-25, 2019.

VEIGA, J. E. Delimitando a agricultura familiar. Reforma Agrária, v. 25, n. 2-3, p. 128-141, 1995.

VELOSO, F. Redes locais e mercados institucionais de compra da agricultura familiar nos municípios de Adamantina, Paulicéia e Tupi Paulista (SP). Tese (Doutorado) - Universidade Estadual Paulista, São Paulo, 2017. Disponível em: <https://bit.ly/2S7emQC>. 
Texto para

Discussão

2606 Execução do Programa de Aquisição de Alimentos nos Municípios Brasileiros

\section{APÊNDICE A}

O apêndice, encontra-se disponível em: https://www.ipea.gov.br/portal/images/stories/ PDFs/TDs/201026_td_2606_apendice_a.pdf 
Ipea - Instituto de Pesquisa Econômica Aplicada

\title{
EDITORIAL
}

\section{Coordenação}

Reginaldo da Silva Domingos

Assistente de Coordenação

Rafael Augusto Ferreira Cardoso

\section{Supervisão}

Camilla de Miranda Mariath Gomes

Everson da Silva Moura

\section{Editoração}

Aeromilson Trajano de Mesquita

Cristiano Ferreira de Araújo

Danilo Leite de Macedo Tavares

Herllyson da Silva Souza

Jeovah Herculano Szervinsk Junior

Leonardo Hideki Higa

\section{Capa}

Danielle de Oliveira Ayres

Flaviane Dias de Sant'ana

\section{Projeto Gráfico}

Renato Rodrigues Bueno

The manuscripts in languages other than Portuguese published herein have not been proofread.

\author{
Livraria Ipea \\ SBS - Quadra 1 - Bloco J - Ed. BNDES, Térreo \\ 70076-900 - Brasília - DF \\ Tel.: (61) 2026-5336 \\ Correio eletrônico: livraria@ipea.gov.br
}



Composto em adobe garamond pro 12/16 (texto) Frutiger 67 bold condensed (títulos, gráficos e tabelas) Brasilia-DF 



\section{Missão do Ipea}

Aprimorar as políticas públicas essenciais ao desenvolvimento brasileiro por meio da produção e disseminação de conhecimentos e da assessoria ao Estado nas suas decisões estratégicas.

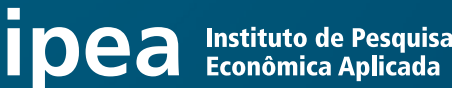 \\ MINISTÉRIO DA \\ ECONOMIA

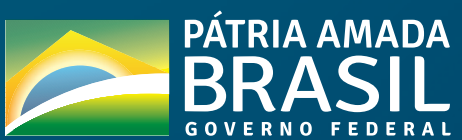

